HERNÁNDEZ, HÉCTOR. "La introducción de la responsabilidad penal de las personas jurídicas en Chile".

Polít. crim. Vol. 5, No 9 (Julio 2010), Art. 5, pp. 207-236.

[http://www.politicacriminal.cl/Vol_05/n_09/Vol5N9A5.pdf]

\title{
La introducción de la responsabilidad penal de las personas jurídicas en Chile*
}

\author{
Dr. Héctor Hernández Basualto \\ Profesor de Derecho Penal de la Universidad Diego Portales \\ hector.hernandez@udp.cl
}

A la memoria de

Sergio Politoff Lifschitz

\section{Resumen}

El artículo analiza críticamente los aspectos centrales de la Ley $\mathrm{N}^{0} 20.393$, de fines de 2009, que introduce por primera vez la responsabilidad penal de las personas jurídicas en el derecho chileno. Luego de la descripción del contexto en que surge la ley, marcado por las exigencias para el ingreso de Chile como miembro pleno a la OCDE, se aborda principalmente el modelo de "responsabilidad por defecto de organización" elegido por el legislador chileno y sus alcances más relevantes. Por último, no obstante una valoración en general favorable, se señalan los desafíos y riesgos que deberá sortear la aplicación práctica de la nueva ley.

\section{Palabras clave}

Criminalidad de empresa, responsabilidad penal de las personas jurídicas, responsabilidad por defecto de organización

\begin{abstract}
The paper critically reviews the core aspects of Chilean Act $\mathrm{N}^{\circ} 20.393$, enacted at the end of 2009, which for the first time in this country introduces a provision on criminal liability of legal entities. After a brief account of the political context that led to this legal innovation in Chile, marked by its need to comply with the requirements to become a full member of OECD, the paper focuses on the liability model chosen by the Chilean legislator - the so called "liability based on organizational fault" model, and its main consequences. Finally, and notwithstanding a general positive opinion of it, the author points at the risks and challenges the Act will face in its enforcement process.
\end{abstract}

\section{Key words}

Corporate crime, corporate criminal liability, liability based on organizational fault

\footnotetext{
* Con ajustes formales mínimos, el artículo corresponde a la contribución del autor al libro colectivo "Chile en el club de los países desarrollados: oportunidades y desafíos del ingreso a la OCDE”, preparado por el Centro de Estudios Internacionales de la Pontificia Universidad Católica de Chile, la Facultad de Derecho de la misma Universidad y el Grupo de Estudio contra la Corrupción de la Universidad de Salamanca.
} 
HERNÁNDEZ, HÉCTOR. "La introducción de la responsabilidad penal de las personas jurídicas en Chile".

\section{Contexto, legitimidad y ámbito de aplicación de la Ley $\mathrm{N}^{\circ} \mathbf{2 0 . 3 9 3}$}

Sin duda la consecuencia más significativa en materia penal de los esfuerzos de Chile por incorporarse a la OCDE ha sido la introducción de la responsabilidad penal de las personas jurídicas, a través de la Ley $\mathrm{N}^{\mathrm{o}} 20.393$, de 2 de diciembre de 2009. ${ }^{1}$ Si bien con anterioridad el ordenamiento chileno había previsto esporádicamente sanciones en las que, en cuanto impuestas por tribunales penales y con efecto directo sobre las personas jurídicas, podían verse genuinas penas contra las mismas, ${ }^{2}$ es la primera vez que esto se hace de un modo tan abierto y explícito, de la mano, además, del establecimiento de un verdadero sistema de responsabilidad penal propio de tales entidades, con explicitación de los presupuestos específicos de la misma y de las circunstancias que la modifican, con penas y reglas de determinación también específicas y con las adaptaciones procesales básicas para su aplicación práctica. ${ }^{3}$

Con esto se abandona - de un modo radical y, en buena medida, sorpresivo - el dogma tradicional societas delinquere non potest, consagrado legislativamente con carácter general en el art. 58 del Código Procesal Penal (en lo sucesivo, CPP) ${ }^{4}$ lo que en concreto sólo puede explicarse por el afán de cumplir oportunamente con las exigencias de las que dependía la incorporación de Chile a la OCDE, en particular de las contenidas en la Convención de dicho organismo en materia de cohecho de servidores públicos extranjeros en transacciones comerciales internacionales, de 21 de noviembre de 1997. Porque, en efecto, atendido el conocido desinterés del legislador chileno por atacar la criminalidad de

\footnotetext{
${ }^{1}$ Las restantes innovaciones, correspondientes a la extensión del campo de aplicación de algunas figuras penales preexistentes (cohecho activo), son, en comparación, de muy escasa significación.

${ }^{2}$ Especialmente expresivo era el art. 173 de la Ley $\mathrm{N}^{\circ} 13.305$, de 6 de abril de 1959, cuyo inciso tercero preveía la "pena accesoria" de disolución (cancelación, revocación de autorización de existencia o disolución anticipada) de la persona jurídica en caso de reincidencia en conductas monopólicas, modelo que, si bien subsistió en lo fundamental hasta 2003 en el primitivo art. $3^{\circ}$ del DL 211, de 22 de diciembre de 1973 ("Ley Antimonopolios"), lo hizo sin explicitación del carácter penal de la sanción, como es la regla en los ejemplos propuestos por la doctrina. E incluso en el caso de la Ley $\mathrm{N}^{\circ} 13.305$ podría haberse discutido si no se trataba, en rigor, de una pena accesoria contra las personas naturales responsables.

${ }^{3}$ Al margen de cualquier valoración de fondo, es un acierto en sí que se hayan desechado soluciones más ambiguas que, ya por lo mismo, acarrean serios problemas interpretativos. Tal es el caso paradigmático del conjunto que forman en el Código español las "consecuencias accesorias" del art. 129 y la imposición del pago solidario de la multa en el art. 31.2. Al respecto SILVA SÁNCHEZ, Jesús María, "La responsabilidad penal de las personas jurídicas y las consecuencias accesorias del art. 129 del Código penal", Manuales de Formación Continuada, № 14 (2001), pp. 307-364, passim; SILVA SÁNCHEZ, Jesús María, "La aplicación judicial de las consecuencias accesorias para las empresas", InDret, 2/2006, pp. 1-15, passim, en: http://www.indret.com/pdf/342 es2.pdf [visitado el 22.03.2010]; BACIGALUPO, Silvina, "Las consecuencias accesorias aplicables a las personas jurídicas en el Código penal de 1995", en: BACIGALUPO, Enrique (Director), Curso de derecho penal económico, Madrid - Barcelona: Marcial Pons, 1998, pp. 65-86, passim; GÓMEZ-JARA DIEZ, Carlos, "El nuevo artículo 31.2 del Código penal", en: GÓMEZ-JARA DÍEZ, Carlos (Editor), Modelos de autorresponsabilidad empresarial, Cizur Menor: Thomson-Aranzadi, 2006, pp. 239-309, passim.

4 "La responsabilidad penal sólo puede hacerse efectiva en las personas naturales. Por las personas jurídicas responden los que hubieren intervenido en el acto punible, sin perjuicio de la responsabilidad civil que las afectare". La disposición, como se sabe, reproduce en lo fundamental el inciso segundo del art. 39 (originalmente 59) del Código de Procedimiento Penal de 1906.
} 
Polit. crim. Vol. 5, № 9 (Julio 2010), Art. 5, pp. 207-236. [http://www.politicacriminal.cl/Vol_05/n_09/Vol5N9A5.pdf]

empresa, ${ }^{5}$ la postura poco entusiasta y más bien renuente del conjunto de la doctrina nacional hacia la punibilidad de las personas jurídicas ${ }^{6}$ y la escasez previa de iniciativas legislativas en ese sentido, ${ }^{7}$ sin el factor externo hubiera sido apenas imaginable un giro tan radical. No es casual, entonces, la importancia que el Mensaje del Ejecutivo (Boletín 6423$07)^{8}$ le atribuye no ya al cumplimiento de compromisos internacionales, sino específicamente al inminente ingreso como miembro pleno de la OCDE, ${ }^{9}$ importancia que se destacó a lo largo de toda la tramitación. No es otra cosa lo que explica que un proyecto tan complejo y sobre una materia tan delicada se haya despachado íntegramente en escasos siete meses de tramitación parlamentaria, ${ }^{10}$ justo a tiempo para exhibirlo a la OCDE: se trataba de un "desafío-país" que había que superar a como diera lugar.

${ }^{5}$ Al respecto HERNÁNDEZ, Héctor, "Perspectivas del derecho penal económico en Chile", Persona y Sociedad, Vol. XIX No 1 (2005), pp. 101-134, p. 119 y ss.

${ }^{6}$ Antes de la coyuntura de la incorporación de la OCDE en la literatura al parecer sólo habían abogado abiertamente por la introducción de dicha punibilidad SILVA, Pedro, "La responsabilidad penal de las personas jurídicas", Revista de Ciencias Penales, T. IV (1938), pp. 317-329, passim; POLITOFF, Sergio, "El 'autor detrás del autor'. De la autoría funcional a la responsabilidad penal de las personas jurídicas", en: POLITOFF, Sergio; MATUS, Jean Pierre (Coords.), Gran criminalidad organizada y tráfico ilícito de estupefacientes, Santiago: ConoSur, 2000, pp. 333-414, p. 398 y ss.; BUSTOS, Juan, "Perspectivas actuales del derecho penal económico", Gaceta Jurídica, No 132 (1991), pp. 7-15, p. 13; y luego en BUSTOS, Juan, "La responsabilidad penal de las personas jurídicas", en: MAIER, Julio; BINDER, Alberto (Compiladores), El derecho penal hoy. Homenaje al Prof. David Baigún, Buenos Aires: Editores del Puerto, 1995, pp. 15-26, p. 23 y ss.; y ONFRAY, Arturo, "Reflexiones en torno a la responsabilidad penal de las personas jurídicas", Revista de Derecho (CDE), $\mathrm{N}^{\circ} 4$ [No 1 del año 2] (2001), pp. 153-167, passim. La tendencia general era la descripción del estado de la discusión y de la solución del derecho vigente, con aprobación explícita de varios autores, como NOVOA, Eduardo, Curso de derecho penal chileno, T. I, Santiago: Editorial Jurídica de Chile, 1960, p. 238; ETCHEBERRY, Alfredo, Derecho penal, $3^{\circ}$ edición, T. I, Santiago: Editorial Jurídica de Chile, 1998, p. 176; CURY, Enrique, Derecho penal. Parte general, $7^{\circ}$ edición, Santiago: Ediciones Universidad Católica de Chile, 2005, p. 91; COUSIÑO, Luis, Derecho penal chileno, T. I, Santiago: Editorial Jurídica de Chile, 1975, pp. 276 a 278, 281; GARRIDO, Mario, Derecho penal, T. II, Santiago: Editorial Jurídica de Chile, 1992, p. 56 y s.; DEL VILLAR, Waldo, Manual de derecho penal. Parte general, Valparaíso: Edeval, 1985, p. 57 y ss.; MORENO, Carlos, "Responsabilidad penal de las personas jurídicas, sus órganos y directivos en derecho penal económico", Revista Entheos, Año 2, No 1 (2004), pp. 43-69, p. 59; y al menos aparentemente implícita en otros como DEL RÍO, J. Raimundo, Derecho penal, T. II, Santiago: Nascimento, 1935, p. 22; NÁQUIRA, Jaime, Derecho penal. Teoría del delito, Santiago: McGraw-Hill, 1998, p. 43 y ss.; ORTIZ, Luis, "Delincuencia económica", en: AA. VV., Problemas actuales de derecho penal, Temuco: Universidad Católica de Temuco, 2003, pp. 191-226, p. 221.

${ }^{7}$ Hasta donde se alcanza a ver, sólo el Proyecto Silva-Labatut de 1938 consideró la introducción de la responsabilidad penal de las personas jurídicas (Título VII del Libro I, arts. 93 a 100). El proyecto se puede consultar en Revista de Ciencias Penales, T. IV (1938), p. 79 y ss. En materia de lavado de dinero se cuenta una moción del senador Orpis (Boletín 5056-07), de efímera tramitación (presentado el 9 de mayo de 2007 y retirado el 5 de junio del mismo año) y en materia ambiental (aunque con potenciales efectos generales) una del senador Ávila (Boletín 6204-07), de 14 de noviembre de 2008, en actual tramitación.

${ }^{8}$ Las citas a los materiales legislativos no se harán conforme a la paginación de los documentos originales, sino a la de la compilación "Historia de la Ley 20.393", preparada por la Biblioteca del Congreso Nacional y disponible en: http://recursoslegales.bcn.cl/jspui-rl/bitstream/10221.3/3894/1/HL20393.pdf [visitado el 08.03.2010] (abreviado: "Historia").

${ }^{9}$ Historia, p. 6 y ss. El propio Mensaje recuerda que al menos otros cinco convenios internacionales imponen a Chile una obligación similar ("Historia", cit. nota $n^{\circ}$ 8, p. 5), ninguno de los cuales, sin embargo, logró lo que - también a su respecto, como se verá - logró la Convención de la OCDE.

${ }^{10} \mathrm{El}$ Mensaje es de 16 de marzo y el oficio que informa al Ejecutivo la aprobación del proyecto por ambas cámaras es de 27 de octubre, debiendo destacarse, además, que 2009 fue "año electoral". 


\section{HERNÁNDEZ, HÉCTOR. “La introducción de la responsabilidad penal de las personas jurídicas en Chile".}

Curiosamente la Convención no prescribe el establecimiento de una responsabilidad penal de las personas jurídicas, sino sólo que las sanciones que en virtud de la misma se impongan a dichas personas sean "eficaces, proporcionadas y disuasivas". ${ }^{11}$ En el caso chileno, sin embargo, la ausencia de un sistema realmente efectivo de sanciones extrapenales para estas entidades ${ }^{12}$ y el tratamiento previo poco diligente del asunto por parte de las autoridades responsables, ${ }^{13}$ unido probablemente a una cierta preferencia de la Convención - y de los órganos de control de su cumplimiento - por el establecimiento de una responsabilidad penal hizo que en algún momento de las negociaciones el campo de maniobra del Estado chileno se redujera al mínimo y en los hechos sólo resultara satisfactorio un mecanismo inserto en el sistema de justicia criminal, por lo demás el único disponible con la cobertura necesaria para cumplir a tiempo. ${ }^{14}$ En este contexto, además, y en concordancia con el modelo adoptado, la más elemental honestidad impuso reconocer el carácter penal de la responsabilidad atribuida a las entidades. ${ }^{15}$

${ }^{11}$ El art. 2 de la Convención prescribe: "Cada parte tomará las medidas necesarias, de acuerdo con sus principios legales, para establecer la responsabilidad de las personas morales por el cohecho a un servidor público extranjero". Por su parte, el art. 3.2 es mucho más claro al disponer: "Si, dentro del sistema jurídico de una de las Partes, la responsabilidad penal no es aplicable a las personas morales, esta Parte deberá asegurar que éstas queden sujetas a sanciones eficaces, proporcionadas y disuasivas de carácter no penal, incluyendo sanciones pecuniarias, en casos de cohecho a servidores públicos extranjeros".

12 A esta conclusión se llegó luego de considerar los muy reducidos alcances de las normas civiles y mercantiles que permiten a la autoridad poner término a la existencia de la persona jurídica (cancelación de la personalidad jurídica de las corporaciones, disolución por revocación de autorización de existencia de algunos tipos de sociedades), así como, especialmente, el carácter fragmentario (tanto en cuanto a la materia como al tipo de entidad) del sistema administrativo de control y eventual represión de personas jurídicas en Chile. Al respecto véanse los Informes de Evaluación del cumplimiento de la Convención para la Fase 1 (DOC. I938/03, pp. 18 y 73) y para la Fase 2 (DOC. I-713/07, pp. 103 y 110), ambos citados conforme a la traducción oficial del Ministerio de Relaciones Internacionales. Como se ve, se trata lisa y llanamente de la ausencia de un verdadero sistema de sanciones extrapenales para las personas jurídicas, y no de su menor "efecto comunicacional", como sugirió Jean Pierre Matus en el Senado, "Historia", cit. nota n 8, p. 199, criterio, por lo demás, poco compatible con la letra del art. 3.2 de la Convención, que expresamente prevé la suficiencia de sanciones extrapenales. El conjunto de las opiniones de este autor sobre la materia se encuentra ahora, con mayores referencias, en MATUS, Jean Pierre, "Informe sobre el proyecto de ley que establece la responsabilidad legal de las personas jurídicas en los delitos de lavado de activos, financiamiento del terrorismo y delitos de cohecho que indica, Mensaje 018-357”, Ius et Praxis, año 15, No 2 (2009), pp. 285306, passim.

${ }^{13}$ Durante la Fase 1 del proceso de evaluación (2003) las autoridades chilenas informaron a la OCDE que se había encomendado a la Comisión Foro Penal la preparación de una propuesta sobre el tema, la que debía estar lista a más tardar a fines de 2004 (Informe Fase 1, pp. 18 y 73), en circunstancias que dicha instancia nunca recibió encargo alguno en ese sentido. La constatación de ese hecho durante la Fase 2 (2007), así como que no se hubieran adoptado medidas alternativas adecuadas en el tiempo intermedio (Informe Fase 2, p. 102 y ss.), llevó a la comisión a expresar su preocupación por el "sostenido incumplimiento" por parte de Chile de los arts. 2 y 3 de la Convención (pp. 106, 110, 130) y contribuyó a que se decidiera, por "la gravedad de la situación observada en Chile", realizar excepcionalmente una Fase 1 bis de revisión de la evolución legislativa (p. 131).

${ }^{14}$ La escasa viabilidad de generar un sistema sancionatorio administrativo fue recalcada durante la tramitación especialmente por René Abeliuk, "Historia", cit. nota ${ }^{\circ} 8$, pp. 37, 180 y ss.

${ }^{15}$ El Proyecto del Ejecutivo consagraba una "responsabilidad legal" de las personas jurídicas, denominación que fue prontamente abandonada ya en la Cámara (Historia, p. 58) por la crítica general que suscitó entre los especialistas consultados, quienes, al margen de cualquier valoración del hecho mismo de consagrarse una tal responsabilidad, no podían sino constatar que era eso y no otra cosa lo que el proyecto hacía. 
Polit. crim. Vol. 5, No 9 (Julio 2010), Art. 5, pp. 207-236.

[http://www.politicacriminal.cl/Vol_05/n_09/Vol5N9A5.pdf]

De este modo la Ley N 20.393 vino a zanjar una cuestión crucial para la configuración del ordenamiento penal chileno en un contexto de urgencia, con poco espacio para una reflexión académica profunda al respecto, tanto sobre el hecho mismo del paso hacia el societas delinquere potest como, sobre todo, una vez adoptada la decisión política en ese sentido, sobre los términos más adecuados para expresar dicha decisión. ${ }^{16}$ Dadas estas circunstancias poco propicias, ciertamente debe celebrarse que el resultado del trabajo legislativo parezca en lo fundamental acertado, ${ }^{17}$ como luego se tratará de justificar al hilo del análisis crítico de la ley que constituye el objeto de este trabajo.

Sin embargo, ni el ineludible acto de autoridad legislativa ni su inserción en una tendencia muy nítida en el derecho comparado, ${ }^{18}$ que da cuenta de cómo el debate político-criminal parece haberse resuelto ampliamente a favor de la responsabilidad penal de los entes colectivos, autorizan a desentenderse del todo de la discusión en cuanto al si de dicha responsabilidad. Porque si bien en las actuales condiciones sociales, ante la existencia de estructuras y dinámicas criminógenas propias de las organizaciones, se consideran insuficientes las sanciones a los individuos - muchas veces fungibles - que actúan por o para ellas, en tanto que la preferencia por las sanciones penales en desmedro de las sanciones administrativas ${ }^{19}$ se funda sobre todo en el mayor efecto simbólico de las primeras, ${ }^{20}$ potencialmente algunas de las objeciones contra la solución legal pueden incidir todavía en la aplicación práctica de la misma, en cuanto sugieren compromiso de garantías fundamentales y, con ello, una posible inconstitucionalidad.

\footnotetext{
${ }^{16}$ El escaso genuino debate académico sobre el proyecto - y sólo respecto del si de la responsabilidad penal de las empresas, no del cómo - tuvo lugar en rigor una vez que éste ya había sido despachado por el Congreso Nacional. Véanse al respecto especialmente las opiniones vertidas a fines de 2009 en "El Mercurio" - como columna de opinión o carta al director - por Enrique Cury (12 y 23 de noviembre), Clara Szczaranski (18 de noviembre), Luis Ortiz (15 de diciembre) y Jean Pierre Matus (14 de noviembre, 27 de noviembre y 17 de diciembre).

17 Gracias tanto al buen criterio en la valoración, elección y adaptación de los modelos comparados disponibles por parte de quienes prepararon el proyecto, como a las valiosas aportaciones de los especialistas invitados a las comisiones del Congreso.

18 Podría decirse que también en el derecho internacional, pero lo cierto es que los instrumentos internacionales suelen emplear formulaciones que dejan espacios de libertad a los Estados. Entre los países desarrollados que contemplan responsabilidad penal de las personas jurídicas destacan, junto a los de la tradición del common law (como Reino Unido, Irlanda, Estados Unidos, Canadá y Australia), cada vez más países de tradición continental como Francia, Holanda, Dinamarca, Bélgica, Suiza o Japón, sin contar con soluciones que si bien nominalmente no consagran responsabilidad penal, la sugieren fuertemente, como ocurre en Austria o, sobre todo, en Italia. Panoramas de derecho comparado se encuentran en BACIGALUPO, Silvina, La responsabilidad penal de las personas jurídicas, Barcelona: Bosch, 1998, pp. 314 y ss.; ZÚÑIGA RODRÍGUEZ, Laura, Bases para un modelo de imputación de responsabilidad penal a las personas jurídicas, $2^{\circ}$ edición, Cizur Menor: Thomson-Aranzadi, 2003, pp. 102 y ss. (también con referencias a derecho iberoamericano); más recientemente EIDAM, Gerd, Unternehmen und Strafe, 3. Aufl., Köln: Luchterhand, 2008, pp. 263 y ss.

${ }^{19}$ Sin perjuicio de que pueda hacerse presente que la persecución penal, en cuanto rodeada de mayores garantías y con menores posibilidades de especialización, puede resultar en los hechos menos eficiente que la administrativa, sobre todo si los órganos encargados de esta última pueden ser dotados de facultades intrusivas al menos aproximadas a las del Ministerio Público.

${ }^{20}$ Compárese, por ejemplo, incluso hoy, el efecto simbólico de la multa más alta impuesta por una Superintendencia, con la simple imposición por parte del juez de garantía de una medida - ¡que no supone condena! - en el contexto de una suspensión condicional del procedimiento
} 


\section{HERNÁNDEZ, HÉCTOR. “La introducción de la responsabilidad penal de las personas jurídicas en Chile".}

Particularmente, si se prescinde de objeciones más bien pintorescas, ${ }^{21}$ si llegara a concluirse que, como sostienen muchos críticos, la responsabilidad penal de los entes colectivos es incompatible con los conceptos aceptados de culpabilidad, podría apreciarse una vulneración del principio de culpabilidad, al que, no obstante su déficit de consagración expresa, se le reconoce en general rango constitucional. ${ }^{22}$ Todo parece indicar, sin embargo, que la posible objeción de inconstitucionalidad tendría poco asidero.

Un indicio de esto es el hecho de que, en general, nadie ponga en duda entre nosotros la legitimidad de la imposición a las personas jurídicas de sanciones administrativas que, por lo demás, suelen ser de contenido equivalente al de las penas previstas por la nueva ley. Porque de ser correcta la vulneración del principio de culpabilidad, en cuanto se admite crecientemente que dicho principio rige también en el orden de las sanciones administrativas, ${ }^{23}$ habría que reconocer, en consecuencia, que tampoco sería posible sancionar a las entidades en ese orden. ${ }^{24}$ Visto que nadie parece dispuesto a asumir esa conclusión, no es descabellado pensar que lo que está en juego no es, en rigor, la

${ }^{21}$ Como aquélla conforme a la cual asignarle carácter de pena a sanciones distintas de la privación o restricción de la libertad ambulatoria, como son necesariamente las que se pueden imponer a una persona jurídica, impediría distinguir entre sanciones penales y administrativas (así, por el Instituto Libertad y Desarrollo, Axel Buchheister en el Senado, "Historia", cit. nota n 8, pp. 216 y ss.). Como es obvio, el razonamiento confunde dos cuestiones diferentes, porque si bien existe consenso (correctamente, aunque cabe recordar que sin base en texto expreso de la Constitución) en que la sanción de privación de libertad sólo se puede imponer en el orden penal, de modo que constituye un factor absoluto de distinción entre pena y sanción administrativa, al mismo tiempo nadie duda que las penas pueden consistir en algo distinto del encierro, cuyo contenido puede ser por cierto coincidente con el de las sanciones administrativas, contexto en el cual se reconoce que la delimitación es formal y está dada, a menos que la propia ley sugiera otra cosa, por el órgano competente para aplicar la sanción (autoridad administrativa o tribunal sin competencia criminal, en un caso; tribunales penales, en el otro). En otras palabras, que el encierro sólo se pueda imponer en sede penal no significa que en dicha sede sólo se pueda imponer encierro. Respecto de las multas, la objeción es tanto más sorprendente a la luz de la convivencia - no histórica, sino absolutamente actual (¡Libro III del Código Penal, procedimiento monitorio!) - de multas penales y multas administrativas. Que la decisión sobre si un hecho acarreará sanción penal o sanción administrativa no sea de competencia del legislador ("Historia", cit. nota $n^{\circ} 8$, p. 217) es, por último, una opinión tan insólita y problemática - más allá, por cierto, de su núcleo pacífico consistente en que no puede haber privación de libertad administrativa - que seguramente se debe al calor del debate y, por lo mismo, no parece merecer mayor atención.

${ }^{22}$ Una síntesis de la discusión chilena en HERNÁNDEZ, Héctor, "El régimen de la autointoxicación plena en el derecho penal chileno: deuda pendiente con el principio de culpabilidad", Revista de Estudios de la Justicia, No 9 (2007), pp. 11-45, pp. 18 y ss.

${ }^{23}$ Entre nosotros CURY, Enrique, "Algunas reflexiones sobre la relación entre penas penales y administrativas", Boletín de Investigaciones de la Facultad de Derecho de la Pontificia Universidad Católica de Chile, No 44/45 (1979/1980), pp. 86-94, p. 91; VERGARA, Alejandro, "Esquema de los principios del derecho administrativo sancionador", Revista de Derecho (UCN-Coquimbo), año $11 \mathrm{~N}^{\circ} 2$ (2004), pp. 137147, p. 143; ALCALDE, Enrique, "Relaciones entre la pena administrativa y la sanción penal", Revista de Derecho Administrativo Económico, № 14 (2005), pp. 29-34, p. 31. Esta interpretación ha ganado fuerza con la jurisprudencia del Tribunal Constitucional (Roles $\mathrm{N}^{\circ} 46, \mathrm{~N}^{\circ} 244, \mathrm{~N}^{\circ} 437, \mathrm{~N}^{\circ} 479$ y $\mathrm{N}^{\circ} 480$ ), que si bien no se refiere al principio de culpabilidad, declara que los principios constitucionales del orden penal deben aplicarse por regla general al derecho administrativo sancionador. En relación con la exigencia de dolo o culpa existirían atisbos de jurisprudencia ordinaria: al respecto, al margen de que en el análisis concreto aplique un concepto erróneo de dolo penal, RIED, José Miguel, "El caso Consorcio 2 - Banco de Chile: información privilegiada y potestad sancionatoria de la administración”, Sentencias Destacadas, 2005, pp. 3144 , p. 38 y ss.

${ }^{24}$ Lo hizo presente certeramente POLITOFF, “El 'autor detrás del autor’”, cit. nota no 6, pp. 123, 406 y ss. 
Polit. crim. Vol. 5, № 9 (Julio 2010), Art. 5, pp. 207-236.

[http://www.politicacriminal.cl/Vol_05/n_09/Vol5N9A5.pdf]

legitimidad intrínseca de la sanción, sino sólo una determinada convicción en cuanto a lo que puede denominarse pena y responsabilidad penal, convicción terminológica que, más allá de sus posibles bondades, en cuanto tal, obviamente, carece de protección constitucional. En todo caso, en la medida en que es posible y razonable fundar una diversa necesidad de legitimación entre el orden penal y el administrativo en virtud de la diversa gravedad - en último término, ante sanciones idénticas, del diverso status simbólico - de lo que se denomina pena, de todos modos debe abordarse el examen de la conformidad de la responsabilidad penal de las personas jurídicas con el principio de culpabilidad como garantía constitucional específicamente penal. ${ }^{25}$

Al respecto lo primero que cabría destacar es que es al menos discutible que una garantía de este tipo rija también para las personas jurídicas y, en todo caso, que rija con la misma intensidad. $^{26}$ Adicionalmente, aunque se esté de acuerdo en que se trata de una garantía pertinente e igualmente intensa, no puede sino reconocerse que a su respecto, por la propia naturaleza del sujeto, sus alcances sólo mutatis mutandi pueden corresponder a los que rigen para las personas naturales, esto es, no puede exigirse identidad, sino sólo equivalencia funcional. ${ }^{27}$

Dicho esto, pareciera que el alcance del principio de culpabilidad que razonablemente pueden reclamar para sí las personas jurídicas, atendida su propia naturaleza, consiste en la proscripción de la responsabilidad objetiva, esto es, de una responsabilidad que no admite que el sujeto pueda eximirse de la misma observando un cierto tipo de comportamiento. ${ }^{28}$ Desde esa perspectiva, podría ser dudosa la compatibilidad con el principio de culpabilidad de un régimen de responsabilidad de la persona jurídica basado exclusivamente en un hecho delictivo ajeno (el del agente individual relacionado con ella), sin atender de ningún modo al comportamiento propio de la misma, ${ }^{29}$ pero no lo es con aquellos modelos que al

\footnotetext{
${ }^{25}$ Así también FEIJÓO SÁNCHEZ, Bernardo, "Sobre el fundamento de las sanciones penales para personas jurídicas y empresas en el derecho penal español y el derecho penal peruano", en: GARCÍA CAVERO, Percy (Coordinador), La responsabilidad penal de las personas jurídicas, órganos y representantes, Lima: ARA, 2002, pp. 215-275, pp. 227 y ss.

${ }^{26}$ Que no todas las garantías constitucionales rigen para las personas jurídicas fluye, desde luego, de la naturaleza de las cosas (proscripción de la tortura, libertad de reunión, entre otras). Más allá de esos límites se impone una reflexión particular sobre el fundamento y los presupuestos de cada garantía. Así, por ejemplo, ni la jurisprudencia estadounidense ni la alemana les reconocen derecho a guardar silencio (infra 3), en tanto que la jurisprudencia española (como la del Tribunal Europeo de Derechos Humanos) matizan a su respecto la inviolabilidad del hogar, al respecto RODRÍGUEZ SOL, Luis, Registro domiciliario y prueba ilícita, Granada: Comares, 1998, pp. 49 y ss., con referencias. Específicamente sobre el principio de culpabilidad, véase NIETO MARTÍN, Adán, La responsabilidad penal de las personas jurídicas, Madrid: Iustel, 2008, pp. 116 y ss., y la importante sentencia del Tribunal Constitucional español 246/1991, de 15 de enero de 1992.

${ }^{27}$ Al respecto (para el concepto mismo de culpabilidad), GÓMEZ-JARA DÍEZ, Carlos, “Autoorganización empresarial y autorresponsabilidad empresarial", Revista Electrónica de Ciencia Penal y Criminología, 08 05 (2006), pp. 1-27, pp. 16 y ss., en: http://criminet.ugr.es/recpc/08/recpc08-05.pdf [visitado el 17.03.2010].

${ }^{28}$ En otras palabras, el comportamiento y la actitud del sujeto son totalmente irrelevantes, porque responde a todo evento.

${ }^{29}$ Tal es el caso de los modelos tradicionales de responsabilidad penal derivada del derecho anglosajón, imperante también en el derecho francés y en el derecho contravencional alemán ( $\$ 30$ OWiG). Cabe llamar la atención, en todo caso, que el Tribunal Constitucional Federal alemán en un célebre obiter dictum en BVerfGE 20, 323 (336), de 25 de octubre de 1966, legitimó ese modelo desde la perspectiva específica del
} 


\section{HERNÁNDEZ, HÉCTOR. "La introducción de la responsabilidad penal de las personas jurídicas en Chile".}

menos en parte hacen depender la responsabilidad de la entidad del comportamiento que ésta adopte, que es, como se verá, el caso en Chile. Desde luego puede objetarse que dicho comportamiento, en cuanto siempre y necesariamente es de los órganos que actúan por ella, es en rigor también un hecho ajeno a la entidad, ${ }^{30}$ pero aunque eso fuera cierto - lo que es rebatido por un sector de la literatura que cree posible ver un comportamiento injusto propio de la organización - con esto se estaría extremando el argumento de la ficción a un punto que se vuelve contraproducente para quienes lo emplean, porque lo que es ficción hasta las últimas consecuencias sencillamente no puede ser titular de garantías fundamentales. ${ }^{31}$ No parece, en consecuencia, que se pueda impugnar con éxito - al menos en sus términos concretos - la constitucionalidad de la decisión legislativa en favor de la responsabilidad penal de las personas jurídicas con base en el principio de culpabilidad. ${ }^{32}$

Otra cuestión - y probablemente la de mayor complejidad - es si la responsabilidad penal de las personas jurídicas es integrable y de qué modo en los actuales términos del sistema dogmático de la teoría del delito, debate que, sin embargo, aquí y por ahora puede quedar sin abordar, porque en el nuevo escenario legislativo queda reducido a un debate "interno" en el seno de la dogmática penal como disciplina teórica, sin consecuencias prácticas inmediatas, al margen de sus legítimas pretensiones de lege ferenda. ${ }^{33}$

principio de culpabilidad, considerando suficiente la culpabilidad de las personas naturales que actúan por la entidad.

${ }^{30}$ Así la crítica de SCHÜNEMANN, Bernd, "La punibilidad de las personas jurídicas desde la perspectiva europea”, Trad. PEÑARANDA RAMOS, Enrique; PÉREZ MANZANO, Mercedes, en: AA. VV., Hacia un derecho penal económico europeo. Jornadas en honor del Prof. Klaus Tiedemann, Madrid: BOE, 1995, pp. 565-600, p. 588; también FEIJÓO SÁNCHEZ, "Sobre el fundamento", cit. nota no 25, p. 228.

31 Sobre esta idea, expresada en el binomio atribución de derechos de ciudadanía / atribución de responsabilidad, NIETO MARTÍN, La responsabilidad penal, cit. nota $\mathrm{n}^{\circ} 26$, p. 107. Que la crítica de Schünemann y Feijóo está menos interesada en la protección de las personas jurídicas que en la preservación de un cierto concepto de responsabilidad penal se aprecia cuando se ve que ambos autores avalan sanciones con otro nombre y fundamento para las personas jurídicas, no necesariamente más exigentes. Véase SCHÜNEMANN, "La punibilidad", cit. nota n $\mathrm{n}^{\circ}$ 30, p. 589 y ss., especialmente p. 591; FEIJÓO SÁNCHEZ, "Sobre el fundamento", cit. nota $\mathrm{n}^{\circ} 25$, pp. 246 y ss.

${ }^{32}$ En relación con otros posibles reparos de constitucionalidad, la objeción tradicional basada en el principio de personalidad de las penas en cuanto a que la pena a la entidad afectaría a terceros inocentes (accionistas, trabajadores, etc.), pasa por alto que ésa es una externalidad negativa de todas las penas (CURY, Derecho penal, cit. nota $\mathrm{n}^{\circ}$ 6, p. 90; NIETO MARTÍN, La responsabilidad penal, cit. nota $\mathrm{n}^{\circ} 26$, p. 108 y ss.). En cuanto a la posible vulneración del ne bis in idem, ésta no se sostiene si, por definición, persona natural y persona jurídica son sujetos distintos, incluso tratándose de empresas muy pequeñas (como, sin embargo, argumentando con el principio de proporcionalidad propone NIETO MARTÍN, La responsabilidad penal, cit. nota ${ }^{\circ} 26$, pp. 110 y ss.).

${ }^{33}$ Sin desconocer en absoluto que se trata de un debate ineludible, asumido que la dogmática, más que la simple relación del derecho vigente, necesariamente equívoco e incompleto, es la reconstrucción conceptual, sistemática y coherente del mismo. Aunque se afirme la legitimidad de la decisión legislativa, debe resolverse si ella - en sus términos concretos, además - obliga a desarrollar una "teoría del delito" diferenciada para las entidades, que al margen de la denominación legal pueda incluso llegar a considerarse una "tercera o cuarta vía" de expresión del derecho penal; o si, por el contrario, es posible integrar la nueva situación en la teoría del delito elaborada inicialmente para las personas naturales y contar con un único sistema de "primera vía". La literatura al respecto es enorme; por sólo mencionar de modo preliminar libros especialmente dedicados al asunto, puede considerarse, la siguiente: HEINE, Günter, Die strafrechtliche Verantwortlichkeit von Unternehmen, Baden-Baden: Nomos, 1995, p. 248 y ss.; ZÚÑIGA RODRÍGUEZ, Bases para un modelo, cit. nota $\mathrm{n}^{\circ}$ 18, p. 216 y ss.; BACIGALUPO, La responsabilidad penal, cit. nota ${ }^{\circ} 18$, p. 148 y ss.; GÓMEZ JARA DÍEZ, Carlos, La culpabilidad penal de la empresa, Madrid - Barcelona: Marcial Pons, 2005; 
Polit. crim. Vol. 5, No 9 (Julio 2010), Art. 5, pp. 207-236.

[http://www.politicacriminal.cl/Vol_05/n_09/Vol5N9A5.pdf]

Por último, en lo que respecta al ámbito de aplicación de la ley, ésta se aplica a todas las personas jurídicas de derecho privado ${ }^{34}$ y a las empresas del Estado (art. $2^{\circ}$ de la Ley $N^{\circ}$ 20.393), ${ }^{35-36}$ sin distinción de tamaño, ${ }^{37}$ en tanto que, en lo que concierne a los delitos que dan lugar a la responsabilidad penal de las mismas, en vez de una previsión general, se consagra un catálogo cerrado de tipos penales, inicialmente los siguientes $\left(\operatorname{art} .1^{\circ}\right)$ :

a) Lavado de dinero (art. 27 de la Ley No 19.913, ley que crea la Unidad de Análisis Financiero). ${ }^{38}$

b) Financiamiento del terrorismo (art. $8^{\circ}$ de la Ley $\mathrm{N}^{\circ} 18.314$, ley sobre conductas terroristas).

c) Soborno o cohecho activo tanto de empleados públicos nacionales (art. 250 del Código Penal [en lo sucesivo, CP]) como de funcionario público extranjero (art. 251 bis CP).

Como se puede ver, se trata de un catálogo extraordinariamente restringido, que en lo fundamental abarca sólo las materias respecto de las cuales existía obligación internacional

GARCÍA CAVERO, Percy, La persona jurídica en el derecho penal, Lima: Grijley, 2008; BAIGÚN, David, La responsabilidad penal de las personas jurídicas, Buenos Aires: Depalma, 2000; MODOLELL, Juan Luis, Persona jurídica y responsabilidad penal, Caracas: Universidad Central de Venezuela, 2002; ZUGALDÍA ESPINAR, José Miguel, Responsabilidad penal de empresas, fundaciones y asociaciones, Valencia: Tirant lo Blanch, 2008. Véanse también los restantes artículos en: GARCÍA CAVERO (Coordinador), La responsabilidad penal, cit. nota ${ }^{\circ} 25$.

${ }^{34}$ Habrá que entender que también a las empresas individuales de responsabilidad limitada (E.I.R.L.), conforme al art. $2^{\circ}$ de la Ley $\mathrm{N}^{\circ} 19.857$.

${ }^{35}$ En lo sucesivo, artículos sin otra mención corresponden a los de la Ley No 20.393.

${ }^{36}$ Las empresas con participación estatal (incluidas las "sociedades estatales") que no constituyen "empresas del Estado" en los términos del inciso segundo del art. $1^{\circ}$ de la Ley $\mathrm{N}^{\circ} 18.575$, Orgánica Constitucional de Bases Generales de la Administración del Estado, deben considerarse personas jurídicas de derecho privado y por esa vía estar cubiertas por la ley, sin que el intenso debate jurídico-administrativo a su respecto deba tener mayores consecuencias en este contexto. Véase LATORRE, Patricio, "Las sociedades estatales en el ordenamiento jurídico chileno", Revista de Derecho (PUCV), T. XXX (2008 - I), pp. 223-240, passim.

${ }^{37} \mathrm{La}$ responsabilidad penal de las entidades se ha fundado en la realidad de empresas de cierta complejidad, por lo que existe preocupación por la suerte de las empresas pequeñas (al respecto NIETO MARTÍN, $L a$ responsabilidad penal, cit. nota $\mathrm{n}^{\circ} 26$, p. 166 y ss.). El proyecto original eximía de responsabilidad ( $\sin$ perjuicio de la designación de un interventor) a las personas jurídicas con menos de 25 empleados y cuyas ventas netas anuales no superaran un cierto límite (art. $6^{\circ} \mathrm{N}^{\circ} 1$ ), criterio que fue criticado por varios especialistas ("Historia", cit. nota n ${ }^{\circ}$ 8, pp. 42 y ss. [Miguel Soto]; 48 [Jean Pierre Matus], 53 [Jorge Bofill] y 55 [Gonzalo Medina]) y desechado en la Cámara de Diputados, por el justo temor de que se convirtiera en mecanismo deliberado para eludir la ley ("Historia", cit. nota $n^{\circ} 8$, pp. 70 y ss.). Como "compensación" se introdujo la norma especial sobre suspensión de la condena que llegaría a ser el art. 29 ("Historia", cit. nota n 8, pp. 96 y ss.), la que, sin embargo, no se refiere expresamente a las empresas pequeñas, sino sólo a que debe considerarse "especialmente el número de trabajadores o las ventas anuales netas o los montos de exportación de la empresa", lo que perfectamente puede entenderse también en favor de las grandes compañías. En cuanto al modelo de prevención se consideraron también algunas concesiones, pero la única que subsistió fue la autorización para que en entidades de ingresos anuales que no excedan de 100.000 UF el encargado de prevención sea el propio dueño o controlador (art. $4^{\circ} 1$ ) letra b]).

${ }^{38}$ Durante el debate legislativo se sostuvo erróneamente que por la vía del lavado de dinero se podía sancionar a las personas jurídicas también por todos los delitos a que se remite esa figura (Juan Carlos Dörr, en la Cámara de Diputados, "Historia", cit. nota ${ }^{\circ} 8$, p. 45; en el mismo contexto pareció sugerirlo también Jorge Bofill, p. 50), lo que implicaba desconocer la diferencia entre "delito-base" y delito de lavado de dinero. 
HERNÁNDEZ, HÉCTOR. "La introducción de la responsabilidad penal de las personas jurídicas en Chile".

de sancionar a las personas jurídicas, las que, por lo demás, tienen una relativa escasa aplicación práctica, sin perjuicio del ámbito no despreciable de aplicación que debería asegurar la consideración del soborno doméstico. Durante la tramitación de la ley se hizo presente reiteradamente que quedaban fuera del catálogo los delitos de mayor trascendencia relacionados con la actividad empresarial. ${ }^{39}$ Sin embargo, las iniciativas para revertir esa situación no fueron acogidas, apelándose para ello a la prudencia inicial que demandaba una innovación tan significativa. ${ }^{40}$ Esta razón podrá no ser muy convincente, pero en cuanto reconoce abiertamente la excesiva circunspección del catálogo, al menos deja la puerta abierta para la futura incorporación de un conjunto de figuras relevantes.

\section{El modelo de responsabilidad de la ley chilena}

Sintéticamente, se conocen dos grandes modelos legislativos ideales de responsabilidad penal de personas jurídicas. Por una parte un modelo de responsabilidad derivada, conforme al cual se hace recaer sobre la persona jurídica la responsabilidad penal de una persona natural ${ }^{41}$ en virtud de algún criterio de conexión entre una y otra, generalmente la circunstancia de ser la persona natural órgano o al menos subordinado del ente moral. ${ }^{42}$ Por la otra un modelo de responsabilidad autónoma u originaria, de acuerdo con el cual la responsabilidad surge directamente de una conexión entre el hecho prohibido y una característica de (o un cierto estado de cosas en) la entidad, siendo irrelevante la eventual responsabilidad de una persona natural. ${ }^{43}$

39 "Historia", cit. nota $n^{\circ}$ 8, pp. 35 (Marta Herrera, por el Ministerio Público), 40 (Fernando Londoño), 42 (Miguel Soto), 48 (Jean Pierre Matus), 54 (Gonzalo Medina) y 191 (María Inés Horvitz).

${ }^{40}$ Véase la discusión sobre las indicaciones presentadas en ese sentido en la Cámara, "Historia", cit. nota $n^{\circ} 8$, pp. 58 y ss.

${ }^{41}$ Sin que esto implique, sin embargo, que la persona natural quede liberada de responsabilidad, como debería ser si se aplicara coherentemente la idea de representación que subyace al modelo. Por esta razón se evita aquí hablar de "transferencia" o "transposición" de responsabilidad, como a veces se hace, giros que pueden sugerir ese efecto que es ajeno al modelo. Tampoco se emplea la habitual expresión "modelo de imputación", porque en rigor todo modelo de responsabilidad es un modelo de imputación. De hecho, durante la tramitación legislativa en Chile ambas expresiones se usaron siempre como sinónimas.

${ }^{42}$ Éste es el caso de la larga tradición anglosajona, caracterizada por una fuerte tendencia a la responsabilidad objetiva, en cuanto, por lo general, dadas las mayores o menores exigencias previstas para la conducta del sujeto individual, se impone sin más responsabilidad a la persona jurídica, cualesquiera que hayan sido las medidas adoptadas por ésta para evitar la comisión del delito. En el caso inglés esto ocurre a través de la llamada "teoría de la identificación" (al respecto GOBERT, James; PUNCH, Maurice, Rethinking corporate crime, London: Butterworths, 2003, p. 59 y ss.), en tanto que en el caso estadounidense, en lo que se da en llamar modelo vicarial (vicarious liability), se da tanto a través de la doctrina del common law del respondeat superior (responsabilidad del superior) como de la influencia más reciente del, algo más restrictivo, highmanagerial test previsto en la sección 2.07 del Código Penal Modelo (al respecto GOBERT / PUNCH, Rethinking, en esta misma nota, p. 55 y ss.; STRADER, J. Kelly, Understanding white collar crime, Newark etc.: LexisNexis, 2002, p. 15 y ss.; GÓMEZ-JARA DÍEZ, Carlos, "Corporate Criminal Liability", en: GARCÍA CAVERO [Coordinador], Responsabilidad penal, cit. nota n ${ }^{\circ}$ 25, pp. 277-327, passim). Una síntesis de ambas tradiciones desde perspectiva continental en NIETO MARTÍN, La responsabilidad penal, cit. nota $\mathrm{n}^{\circ} 26$, p. 88 y ss. En el derecho continental responde a estas características, por ejemplo, la regulación del derecho francés (art. 121-2 CP), al respecto LARGUIER, Jean; CONTE, Philippe, Droit pénal des affaires, $11^{e}$ édition, Paris: Armand Colin, 2004, p. 40 y ss.

${ }^{43} \mathrm{Si}$ bien en doctrina se han formulado algunas propuestas estrictas de autorresponsabilidad - esto es, que al menos en alguna hipótesis prescinden totalmente de factores de conexión con un hecho individual (véase, por ejemplo, HEINE, Die strafrechtliche Verantwortlichkeit, cit. nota $n^{\circ} 33$, p. 316 [versión en castellano en 
Polit. crim. Vol. 5, No 9 (Julio 2010), Art. 5, pp. 207-236.

[http://www.politicacriminal.cl/Vol_05/n_09/Vol5N9A5.pdf]

Se suele hablar también de un modelo mixto, que en rigor no es más que una variante más o menos morigerada de las consagraciones históricas emblemáticas del modelo de responsabilidad derivada, en el sentido de no satisfacerse - al contrario de dichos casos emblemáticos, de marcada tendencia hacia la responsabilidad objetiva - con una conexión meramente formal entre la entidad y la persona natural responsable y exigir, en cambio, algún tipo de "aporte" propiamente organizacional al delito. En la medida, sin embargo, en que la responsabilidad de la persona natural siga siendo presupuesto de la de la persona jurídica, se tratará sin duda de una responsabilidad derivada. ${ }^{44}$

Pues bien, la ley chilena ha abrazado precisamente un modelo atenuado de responsabilidad derivada, que, además de la conexión entre individuo responsable y su hecho con la persona jurídica, requiere que ésta haya contribuido al hecho por la vía de haberse organizado de un modo que favorece o en todo caso no impide ni dificulta la realización de ese tipo de hechos, esto es, la llamada responsabilidad por "defecto de organización". ${ }^{45}$ En efecto,

NIETO MARTÍN, La responsabilidad penal, cit. nota nº 26, p. 136]; y GÓMEZ-JARA DÍEZ, "El nuevo art. 31.2 ", cit. nota $\mathrm{n}^{\circ} 3$, p. 302), el modelo prácticamente no ha conocido consagración legislativa. Se suele mencionar como excepción la responsabilidad imprudente de las entidades en el Código Penal Federal de Australia de 1995 (Criminal Code Act, vigente desde 2000; el texto se encuentra disponible en: http://www.comlaw.gov.au/ComLaw/Legislation/ActCompilation1.nsf/0/1B4A2DD73EF9A4BBCA2576040 024B600/\$file/CriminalCode1995_WD02.pdf [visitado el 12.03.2010]), cuya sección 12.4 (2) dispone que cuando el elemento de culpabilidad no se da en ninguno de los empleados, agentes u oficiales, puede darse en la corporación si la conducta de ésta, vista como un todo, es negligente, agregando luego, en la sección 12.4 (3), criterios de negligencia asociados a defectos de organización. Cabe destacar, sin embargo, que en lo que respecta a la realización del tipo objetivo (comisión del "elemento físico"), conforme a la sección 12.2, la atribución del mismo a la corporación parece suponer en todo caso que sea realizado por un empleado, agente u oficial dentro del marco de su empleo o dentro de su autoridad actual o aparente. Algo similar rige en el Reino Unido para el nuevo "homicidio corporativo" regulado por la Corporate manslaughter and corporate homicide Act 2007 (disponible en: http://www.opsi.gov.uk/acts/acts2007/ukpga_20070019_en_1 [visitado el 03.07.2010]), que si bien representa el abandono de la tradicional teoría de la identificación y ya no exige responsabilidad de ninguna persona natural, sino un grave incumplimiento de deberes de cuidado propios de la organización (sección 1 [1] y [4] [b]), sigue exigiendo expresamente para la condena que un elemento esencial de ese incumplimiento sea, en línea con la tradición, la forma en que el ente ha sido organizado y administrado por su "senior management" (sección 1 [3] y [4] [c]), con lo cual sólo representa una variante atenuada de responsabilidad derivada.

${ }^{44}$ Sólo tiene sentido hablar de un "modelo mixto" - aunque en todo caso de un modo equívoco - en casos de convivencia de ambos modelos en un mismo ordenamiento, lo que, como se tratará de demostrar, no ocurre en el derecho chileno.

${ }^{45}$ En la discusión continental, la idea de "defecto de organización" (o "culpabilidad organizacional") se debe fundamentalmente a TIEDEMANN, Klaus, "Die 'Bebußung' von Unternehmen nach dem 2. Gesetz zur Bekämpfung der Wirtschaftskriminalität", $N J W, 1988$, pp. 1169-1174, p. 1172 y ss., si bien inicialmente como fundamento abstracto, sin potencial de exculpación. Desde un punto de vista de los modelos legislativos, han sido especialmente influyentes, no sin paradoja, las "Directivas de determinación de penas para organizaciones" del derecho federal estadounidense (Sentencing Guidelines for Organisations), de 1991 (modificadas en 2004), disponibles, con notas de aplicación en la forma de un verdadero manual, en: http://www.ussc.gov/2007guid/tabconchapt8.htm [visitado el 25.01.2010] (hay traducción castellana en GÓMEZ-JARA DÍEZ, Carlos, La responsabilidad penal de las empresas en los EE. UU., Madrid: Editorial Universitaria Ramón Areces, 2006, p. 115 y ss.), contexto en el cual, para la determinación del monto de las multas y una posible probation, se valora la organización de la empresa en términos de su apego al derecho, su preocupación por el cumplimiento de la ley, los mecanismos internos de control, las medidas adoptadas con posterioridad al delito, etc. (§8B2.1). Pues bien, pronto se advirtió fuera de las fronteras de los Estados 
HERNÁNDEZ, HÉCTOR. "La introducción de la responsabilidad penal de las personas jurídicas en Chile".

conforme al art. $3^{\circ}$ de la ley los requisitos de la responsabilidad penal por los delitos previstos en el art. $1^{\circ}$ son los siguientes:

a) Que el delito haya sido cometido por personas pertenecientes a un determinado círculo que la propia ley define, a saber, los dueños, controladores, responsables, ejecutivos principales, representantes de la empresa o quienes realicen actividades de administración y supervisión en ella, o bien por otras personas naturales que estén bajo la dirección o supervisión directa de alguno de dichos sujetos.

b) Que los delitos se hayan cometido directa e inmediatamente en interés de la persona jurídica o para su provecho, lo que viene reiterado luego cuando se señala que las entidades "no serán responsables en los casos que las personas naturales indicadas en los incisos anteriores, hubieren cometido el delito exclusivamente en ventaja propia o a favor de un tercero".

c) Y siempre que la comisión del delito sea consecuencia del incumplimiento, por parte de la entidad, de sus deberes de dirección y supervisión, a lo que se opone expresamente la previa adopción e implementación de un modelo de organización, administración y supervisión para prevenir delitos como el cometido, esto es, más sintéticamente, de un modelo de prevención de delitos.

Como se ve, la responsabilidad de la entidad se construye al modo de una forma especial de intervención en el delito cometido por el sujeto relacionado, ${ }^{46}$ razón por la cual responde precisamente por ese título delictivo. ${ }^{47}$

Antes de analizar con algún detalle sus rasgos más sobresalientes, cabe comentar que, desde un punto de vista político más amplio, el modelo de responsabilidad por defecto de organización se inscribe en la estrategia de control del delito vía autorregulación forzada (enforced self-regulation), esto es, imponiéndole a las empresas en cuyo seno se produce la actividad delictiva el deber de organizarse y regularse de modo que sirvan también como instancias de prevención y detección de la misma, concretamente mediante la adopción e implementación de programas de cumplimiento (compliance programs). ${ }^{48}$ Desde luego ése

Unidos que tales criterios no sólo podían ser útiles para definir el quántum de la pena, sino también para resolver sobre la procedencia misma de la punición. El caso más nítido de esta adaptación se da en el derecho italiano, cuya regulación de la "responsabilidad administrativa" de las personas jurídicas por delito (Decreto legislativo $\mathrm{N}^{\circ} 231$, de 8 de junio de 2001) ejerció reconocidamente gran influencia en la preparación del proyecto chileno. Lo mismo rige para la llamada "responsabilidad originaria" por ciertos delitos prevista en el apartado segundo del art. 100 quater del Código suizo introducido en 2003 (hay traducción castellana en GÓMEZ-JARA DÍEZ, “El nuevo art. 31.2”, cit. nota $\mathrm{n}^{\circ}$ 3, p. 303), cuerpo legal donde, además, se da una "responsabilidad subsidiaria (autónoma)" cuando el delito no puede imputarse a ningún individuo precisamente por la deficiente organización empresarial (apartado primero). Al respecto EIDAM, Unternehmen und Strafe, cit. nota $\mathrm{n}^{\mathrm{o}} 18$, p. 278 y ss.

${ }^{46}$ Se prefiere hablar genéricamente de "intervención" para no entrar a la discusión dogmática sobre si, bajo ciertos supuestos, el ente no puede ser considerado también autor del delito (coautor o "autor detrás del autor") y no sólo partícipe.

${ }^{47}$ No se ha establecido, en consecuencia, un delito sui generis propio de las personas jurídicas.

48 No otra cosa es nuestro "modelo de prevención". Véase al respecto la formulación original de BRAITHWAITE, John, "Enforced Self-Regulation: a new strategy for corporate crime control", Mich. L. 
Polit. crim. Vol. 5, № 9 (Julio 2010), Art. 5, pp. 207-236.

[http://www.politicacriminal.cl/Vol_05/n_09/Vol5N9A5.pdf]

es un efecto de cualquier modelo de responsabilidad penal de las personas jurídicas, pero la conexión es mucho más clara y consciente, en particular en lo que concierne a la forma específica de organización, cuando dicha responsabilidad se funda precisamente en el hecho de no haberse organizado y regulado del modo debido.

Si bien no es ésta la primera manifestación entre nosotros de esta estrategia en franca expansión - considérese, por ejemplo, el sistema de prevención del lavado de dinero - ${ }^{49}$ con seguridad es la de alcances más amplios, pues aunque inicialmente son muy pocos los delitos relevantes, los deberes de organización afectan, si bien no a todas las personas jurídicas, sí al menos a todas las empresas. Por lo mismo podrían surgir, tal vez por primera vez entre nosotros, dudas respecto de la legitimidad de un modelo que traspasa a los privados, al menos parcialmente, tareas privativas del Estado como son la prevención, la detección y la investigación del delito, todo esto coactivamente - por la vía de la amenaza de pena $-\mathrm{y}$ sin retribución por los gastos. ${ }^{50} \mathrm{Al}$ respecto cabría replicar, sin embargo, por una parte, que el deber de prevenir delitos en el desarrollo del "giro" de la empresa no es sino consecuencia del sinalagma libertad / responsabilidad aplicado a la actividad empresarial: el ejercicio de la libertad de empresa impone, entre otros, el deber de velar porque el mismo no dé lugar a delitos, ${ }^{51}$ con lo cual sólo cabría discutir la virtud de detalles del modelo concreto, no su legitimidad fundamental. Por otra parte, asumido que el Estado no puede dejar de adoptar medidas eficaces contra la criminalidad de empresa, la alternativa sería reforzar significativamente el control administrativo - tanto previo como $a$ posteriori - de la operación de las entidades, con el consiguiente entorpecimiento de su actividad, de modo que probablemente resulte más conveniente para la empresa - que, como con orgullo se dice en otros contextos, es la que "mejor sabe" cómo hacer bien las cosas - hacerse cargo de la prevención de sus delitos. ${ }^{52}$

Rev., 80 (1981-1982), pp. 1466-1507, passim; también NIETO MARTÍN, La responsabilidad penal, cit. nota n ${ }^{\text {0 } 26, ~ p . ~} 215$ y ss.; NIETO MARTÍN, Adán, "Responsabilidad social, gobierno corporativo y autorregulación: sus influencias en el derecho penal de la empresa", Polit. Crim., No 5 (2008), A3-5, pp. 1-18, passim, en: http://www.politicacriminal.cl/n_05/A 3 5.pdf [visitado el 22.03.2010]; escépticos, entre otros, THEILE, Hans, "Unternehmensrichtlinien: Ein Beitrag zur Prävention von Wirtschaftskriminalität?”, ZIS, 9/2008, pp. 406-418, passim, en: http://www.zis-online.com/dat/artikel/2008_9 261.pdf [visitado el 22.03.2010]; HEFENDEHL, Roland, "Corporate Governance und Business Ethics: Scheinberuhigung oder Alternativen bei der Bekämpfung der Wirtschaftskriminalität? ”, JZ, 2006, pp. 119-125, passim.

${ }^{49}$ Como se sabe, la Ley $\mathrm{N}^{0} 19.913$, además de tipificar el delito de lavado, en lo fundamental impone importantes deberes de organización y colaboración a las empresas susceptibles de usadas como canales para la comisión del delito. Al respecto PRAMBS, Claudio, El delito de blanqueo de capitales, Santiago: LexisNexis, 2005, pp. 22 y ss.

${ }^{50} \mathrm{La}$ constitucionalidad de la estrategia ha sido discutida en el derecho comparado, hasta donde se puede ver con respuesta favorable para la misma. Así, por ejemplo, específicamente para el modelo de prevención del lavado de dinero en Alemania, WERNER, Gerhard, Bekämpfung der Geldwäsche in der Kreditwirtschaft, Freiburg: Iuscrim Edition (MPI), 1996, p. 91 y ss.

51 Sobre la idea central, por todos, FRISCH, Wolfgang, "Problemas fundamentales de la responsabilidad penal de los órganos de dirección de la empresa”. Trad. PAREDES CASTAÑÓN, José Manuel, en: MIR PUIG, Santiago; LUZÓN PEÑA, Diego Manuel (Coordinadores), Responsabilidad penal de las empresas y sus órganos y responsabilidad por el producto, Barcelona: J.M. Bosch, 1996, pp. 99-127, p. 110 y ss.

52 Gana relevancia en este contexto la vieja tesis de TIEDEMANN, Klaus, Wirtschaftsstrafrecht und Wirtschaftskriminalität AT, Reinbek bei Hamburg: Rowohlt, 1976, pp. 79 y ss., en cuanto a que la aplicación del principio de subsidiariedad en materia penal-económica debe tener en cuenta que la conminación penal 
HERNÁNDEZ, HÉCTOR. "La introducción de la responsabilidad penal de las personas jurídicas en Chile".

\subsection{Comisión del delito por parte de un sujeto relacionado}

El primer requisito y factor de conexión del hecho con la persona jurídica consiste en que aquél haya sido cometido por una persona perteneciente a un determinado círculo de personas, compuesto por los dueños, los órganos directivos de la entidad (controladores, responsables, ejecutivos principales, representantes $o$, en general, quienes realicen actividades de administración y supervisión) y cualquier otra persona natural que se encuentre bajo la dirección o supervisión directa de los dueños u órganos directivos. De este modo, la ley chilena establece un círculo amplio de sujetos relacionados, no circunscrito a los órganos directivos, ${ }^{53}$ en tanto que, si bien hace la distinción entre éstos y el personal subordinado, no establece un régimen diferente para los delitos cometidos por una u otra categoría de sujetos. ${ }^{54}$

En la medida en que se trata de un factor necesario pero no suficiente, pierden fuerza los argumentos favorables a un círculo restringido de sujetos relacionados relevantes ${ }^{55}$ y parece preferible esta solución amplia. Y si bien la exigencia de una relación de dirección o supervisión "directa" entre agente y órgano directivo ${ }^{56}$ va en sentido contrario, lo que podría sugerir una exención injustificada de responsabilidad en casos de delegación de funciones, la circunstancia de que entre tales órganos directivos se cuenten genéricamente "quienes realicen actividades de administración y supervisión" permite disipar esas dudas.

Por la misma razón, no se echa tanto de menos la exigencia - en todo caso obvia contenida expresamente en varios ordenamientos en cuanto a que el agente haya actuado, al menos aparentemente, dentro del marco de los fines de la empresa, de sus competencias o de su empleo, entre otras formulaciones. ${ }^{57}$

\subsection{Actuación directa e inmediata en interés de la empresa o para su provecho}

El segundo factor de conexión entre la entidad y el delito consiste en que el sujeto relacionado lo haya cometido en interés o para provecho de aquélla, exigencia con la que en el derecho comparado sólo se quiere excluir que actuaciones que no son susceptibles de

puede ser un mecanismo menos gravoso para el libre desarrollo de la actividad económica que la imposición de un denso sistema de controles extrapenales.

${ }^{53}$ A diferencia de lo que ocurre con la teoría de la identificación inglesa, que exige la comisión por parte de un senior manager, o la letra del Código francés, circunscrito a órganos o representantes (art. 121-2 CP). La jurisprudencia tanto estadounidense como francesa (i) favorecerían la extensión indiscriminada. Véase NIETO MARTÍN, La responsabilidad penal, cit. nota $\mathrm{n}^{\circ} 26$, p. 97.

${ }^{54}$ En el derecho italiano, por ejemplo, la distinción sirve de base para un diverso régimen probatorio, en la forma de una brutal inversión de la carga de la prueba tratándose de delitos cometidos por órganos directivos (cfr. arts. $6^{\circ}$ y $7^{\circ}$ del Decreto Legislativo $\mathrm{N}^{\circ}$ 231/2001). NIETO MARTÍN, La responsabilidad penal, cit. nota $\mathrm{n}^{\mathrm{o}} 26$, p. 95 y ss. habla de un "modelo europeo" al menos en ciernes.

${ }^{55}$ Los que deben entenderse en un contexto de responsabilidad objetiva. Al respecto, NIETO MARTÍN, La responsabilidad penal, cit. nota $\mathrm{n}^{\circ} 26, \mathrm{pp} .91$ y ss.

${ }^{56}$ Introducida a propuesta del senador Espina, Historia, p. 240, con el objeto de precisar lo que consideraba una formulación demasiado amplia.

57 Al respecto, para el derecho estadounidense, GÓMEZ-JARA DÍEZ, "Corporate Criminal Liability”, cit. nota $\mathrm{n}^{\circ}$ 42, p. 297 y ss.; STRADER, Understanding, cit. nota $\mathrm{n}^{\circ}$ 42, p. 17; GOBERT / PUNCH, Rethinking, cit. nota $n^{\circ} 42$, p. 57; más amplio NIETO MARTÍN, La responsabilidad penal, cit. nota n ${ }^{\circ} 26$, p. 99 y ss. 
Polit. crim. Vol. 5, No 9 (Julio 2010), Art. 5, pp. 207-236.

[http://www.politicacriminal.cl/Vol_05/n_09/Vol5N9A5.pdf]

reportarle ningún beneficio, especialmente aquéllas contrarias a los intereses de la organización, le acarreen adicionalmente responsabilidad penal. ${ }^{58}$ Esta idea se ve nublada en el derecho chileno por la poco inteligible exigencia adicional de actuación "directa e inmediata" en ese sentido, ${ }^{59}$ la que, sin embargo, debería entenderse aclarada por el inciso final, que, ahora en términos negativos, sólo deja fuera la comisión del delito "exclusivamente en ventaja propia [del agente] o a favor de un tercero". 60

La redacción adoptada ("en su interés", "para su beneficio") sugiere fuertemente que se trata de una exigencia subjetiva, lo que en principio podría acarrear serias dificultades probatorias. ${ }^{61}$ Aclarado, sin embargo, que la exigencia tiene un sentido negativo, que, por lo mismo, no es incompatible con la existencia de otros propósitos que incluso pueden ser principales, ${ }^{62}$ conforme a las reglas generales de imputación subjetiva, si el hecho objetivamente tiende a beneficiar ${ }^{3}$ - al menos también - a la entidad, dicha imputación debería decaer sólo en hipótesis plausibles de error, las que probablemente serán muy escasas. $^{64}$

\section{3. ¿Hipótesis de responsabilidad autónoma?}

La exigencia de una contribución de la propia persona jurídica al delito, como es el "defecto de organización", puede sugerir la idea de una responsabilidad penal autónoma de la misma, idea que viene reforzada por el art. $5^{\circ}$, que precisamente afirma esa autonomía. ${ }^{65}$ Bien visto, sin embargo, se aprecia que esto puede ser así sólo desde un punto de vista procesal, porque materialmente no hay ninguna hipótesis de responsabilidad de la entidad sin persona natural responsable.

\footnotetext{
${ }^{58}$ GÓMEZ-JARA DÍEZ, “Corporate Criminal Liability”, cit. nota n 42, pp. 300 y ss.

${ }^{59}$ Introducida en el Senado, al parecer a propuesta del Ejecutivo, siguiendo una sugerencia de Miguel Chaves, "Historia", cit. nota n 8, p. 240.

${ }^{60}$ Así también la jurisprudencia estadounidense, GÓMEZ-JARA DÍEZ, “Corporate Criminal Liability”, cit. nota $n^{\circ} 42$, p. 301 .

${ }^{61}$ Así lo hizo notar atinadamente Jean Pierre Matus en ambas cámaras, "Historia", cit. nota n 8, pp. 48 y 204.

${ }^{62}$ Esto es clave, pues de lo contrario habría que reconocer que, si bien es muy discutible, existe una extendida opinión en la discusión comparada conforme a la cual los elementos subjetivos del tipo responden al esquema de exigencias del llamado dolo directo de primer grado o intención, esto es, con total preeminencia del elemento volitivo por sobre el cognoscitivo, de modo que ni aun conocimiento seguro (dolo directo de segundo grado o de las consecuencias necesarias) satisface la exigencia si es que falta el propósito especial, así WARDA, Heinz-Günter, "Grundzüge der strafrechtlichen Irrtumslehre”, Jura, 1979, pp. 1-4, 71-82, 113118, 286-297, p. 4; JAKOBS, Günther, Strafrecht AT, 2. Aufl., Berlin - New York: De Gruyter, 1991, 8/15; véase también SAMSON, Erich, "Absicht und direkter Vorsatz im Strafrecht”, JA, 1989, pp. 449-454, p. 452. En este caso, sin embargo, no se aprecian dificultades para aplicar las reglas generales y hacer bastar el conocimiento del carácter beneficioso de la conducta.

${ }^{63}$ Manifiestamente no es necesario que se produzca efectivo beneficio.

${ }^{64}$ Destaca la objetivización de que es objeto esta exigencia en el derecho comparado NIETO MARTÍN, La responsabilidad penal, cit. nota $\mathrm{n}^{\mathrm{o}} 26, \mathrm{p} .101$.

65 El epígrafe del art. $5^{\circ}$ reza "Responsabilidad penal autónoma de la persona jurídica", en tanto que el comienzo del precepto es del siguiente tenor: "La responsabilidad de la persona jurídica será autónoma de la responsabilidad penal de las personas naturales y subsistirá cuando, concurriendo los demás requisitos previstos en el artículo $3^{\circ}$, se presente alguna de las siguientes situaciones...”.
} 
HERNÁNDEZ, HÉCTOR. "La introducción de la responsabilidad penal de las personas jurídicas en Chile".

En efecto, el art. $5^{\circ}$ no altera el modelo previsto en el art. $3^{\circ}$, sino que se limita a aclarar que el requisito de delito cometido por un sujeto relevante y con la tendencia exigida puede tenerse por cumplido desde que constan fehacientemente sus extremos, aunque no se imponga condena a dicho sujeto. Y no sólo eso. Lo hace en unos términos que - en comparación con lo que se admite en general para estructuras similares - restringen significativa e innecesariamente esa posibilidad, reforzando aún más el carácter derivado y dependiente de la responsabilidad del ente. ${ }^{66}$

Porque si se toma como parámetro lo que rige, por ejemplo, para la relación entre los llamados "delitos de conexión" (receptación, lavado de dinero) y sus respectivos "delitosbase" ${ }^{67}$ o entre los partícipes y el autor, ${ }^{68}$ también debería bastar en este contexto con la constatación de que el sujeto relevante ha realizado un hecho típico y antijurídico con la tendencia requerida, sin necesidad de condena al respecto. Más aún, también aquí se debería asumir que en un ámbito como éste, en que los obstáculos para arribar a condena suelen serlo también para un debate exhaustivo sobre aspectos relevantes para el carácter típico y antijurídico del hecho, como la efectiva ausencia de error de tipo o de causas de justificación, ${ }^{69}$ la actividad probatoria del órgano acusador podrá contentarse por lo general con la comprobación fehaciente de la "tipicidad objetiva", todo esto sin apartarse

\footnotetext{
${ }^{66}$ El principal artífice de este reforzamiento fue Jorge Bofill en su rol de asesor clave en la tramitación del proyecto, especialmente en el Senado. No sólo fustigó los defectos manifiestos del proyecto del Ejecutivo en este punto y veló porque la redacción garantizara que no habría responsabilidad de la entidad sin responsabilidad individual, sino que incluso, a través de una determinada interpretación de las exigencias probatorias para ese fin, apoyó implícitamente la necesidad absoluta de condena ("si no estuviera identificada la persona natural responsable del hecho, tampoco sería posible determinar si se trató de un hecho voluntario o involuntario, doloso o no, por lo que atribuir responsabilidad a la empresa en tal caso, constituiría un mecanismo de responsabilidad objetiva", "Historia", cit. nota n ${ }^{\circ}$, p. 52; en términos similares en p. 213), sin perjuicio de contribuir finalmente a la solución de compromiso que representó la indicación del Ejecutivo cuyo texto llegaría a ser ley (p. 257), aunque siempre convencido de que con ello se iba "más allá" del modelo del art. $3^{\circ}$ ("Historia", cit. nota $\mathrm{n}^{\circ}$ 8, pp. 257 y ss.).

${ }^{67}$ Respecto de la receptación MACKINNON, John, Autoría y participación y el delito de receptación, Santiago: LexisNexis, 2004, p. 235 y s.; respecto del lavado de dinero hay norma expresa en el inciso quinto del art. 27 de la Ley No 19.913 (sobre ello PRAMBS, El delito de blanqueo, cit. nota no 49, p. 303 y ss.), si bien lo mismo debía regir ya bajo la vigencia del art. 12 de la Ley $N^{\circ} 19.366$, conforme a POLITOFF, Sergio, "El lavado de dinero", en: POLITOFF, Sergio; MATUS, Jean Pierre (Coordinadores), Lavado de dinero y tráfico ilícito de estupefacientes, Santiago: ConoSur, 1999, pp. 3-86, p. 71 y s.; MATUS, Jean Pierre, "Informe sobre algunos aspectos sustantivos y procesales del delito de lavado de dinero del art. 12 de la Ley 19.366", en: AA. VV., Informes en derecho, Santiago: Ministerio Público, 2005, pp. 305-319, p. 312 y ss.; HERNÁNDEZ, Héctor, "El delito de lavado de dinero", en: AA. VV., Informes en derecho, en esta misma nota, pp. 321-354, pp. 322 y ss.

${ }^{68}$ Como se sabe, en Chile domina ampliamente la tesis de la "accesoriedad media", conforme a la cual la responsabilidad del partícipe está condicionada sólo por el carácter típico y antijurídico del hecho del autor, no por su culpabilidad. Así NOVOA, Eduardo, Curso de derecho penal chileno, T. II, Santiago: Editorial Jurídica de Chile, 1966, p. 188 y s.; GARRIDO, Derecho penal, cit. nota n ${ }^{\circ}$ 6, p. 330; CURY, Derecho penal, cit. nota $\mathrm{n}^{\circ}$ 6, p. 641 y s.; POLITOFF, Sergio; MATUS, Jean Pierre; RAMÍREZ, María Cecilia, Lecciones de derecho penal chileno. Parte general, $2^{\circ}$ edición, Santiago: Editorial Jurídica de Chile, 2004, p. 422. En general ésta es también la opinión de ETCHEBERRY, Derecho penal, T. II, cit. nota ${ }^{\circ} 6$, p. 80, quien, sin embargo, asume para el encubrimiento la tesis de la accesoriedad máxima (p. 81).

${ }^{69}$ Así como sobre la efectiva concurrencia del propósito de beneficiar a la empresa, si no se le concibe, como se ha sugerido aquí (supra 2.2), como simple expresión de dolo.
} 
Polít. crim. Vol. 5, № 9 (Julio 2010), Art. 5, pp. 207-236.

[http://www.politicacriminal.cl/Vol_05/n_09/Vol5N9A5.pdf]

mayormente de los criterios de racionalidad y legitimidad de nuestra práctica probatoria. ${ }^{70}$ En vez de eso, sin embargo, la ley restringe los casos en que la ausencia de condena de la persona natural no obsta a la responsabilidad de la entidad, a los siguientes:

a) Cuando la responsabilidad penal del sujeto se ha extinguido por su muerte o por la prescripción de la acción penal $^{71}$ (inciso primero $\mathrm{N}^{\mathrm{o}} 1$ ).

b) Cuando se le sobresee temporalmente por su rebeldía o su enajenación sobreviniente $^{72}$ (inciso primero $\mathrm{N}^{\mathrm{o}} 2$ ).

c) Cuando, habiéndose acreditado la existencia del delito, no se logra establecer la identidad del responsable individual, ${ }^{73}$ siempre y cuando "se demostrare fehacientemente que el delito debió necesariamente ser cometido dentro del ámbito de funciones y atribuciones propias" de las personas relevantes ${ }^{74}$ (inciso segundo).

El único supuesto que merece algún comentario especial es el último, aunque no por su fundamento, que es relativamente evidente a la luz de lo que se acaba de explicar, ${ }^{75}$ sino por su formulación concreta. Por una parte, que la ley exija prueba de que el delito debió haberse cometido necesariamente "dentro del ámbito" de funciones y atribuciones de los sujetos relevantes en vez de "por" uno de dichos sujetos, ${ }^{76}$ que es lo que la naturaleza del problema hubiera sugerido, puede dar lugar a importantes dudas interpretativas. En cuanto a que dicho extremo deba estar acreditado "fehacientemente", fórmula con la cual se quiso aludir a una alta exigencia de prueba, ${ }^{77}$ no se aprecia, sin embargo, cómo se puede superar - conceptualmente, que es lo que aquí importa - la exigencia del estándar general de

\footnotetext{
${ }^{70}$ La ausencia de dolo y las causas de justificación (como las de exculpación o disculpa) son reconocidamente excepcionales (por regla general las conductas típicas son antijurídicas, por regla general las personas son imputables y actúan responsablemente, en tanto que en lo que concierne al dolo, sin necesidad de discutir la vigencia y alcances de la presunción del inciso segundo del art. $1^{\mathrm{o}} \mathrm{CP}$, rige lo mismo: por regla general las personas saben y quieren hacer lo que hacen). Por lo mismo, acreditada la tipicidad objetiva, sólo ganan relevancia cuando vienen sugeridas por las circunstancias mismas del hecho o son promovidas plausiblemente por la defensa (duda razonable en los términos del art. $340 \mathrm{CPP}$ ), caso en el cual, conforme al principio in dubio pro reo, es deber del Ministerio Público disiparlas.

${ }^{71}$ Esto es, conforme al art. $93 \mathrm{~N}^{\mathrm{o}} 1 \mathrm{y} \mathrm{N} \mathrm{N}^{\mathrm{o}} 6 \mathrm{CP}$.

${ }^{72}$ Esto es, conforme al art. 252 letras b) y c) CPP.

${ }^{73}$ En rigor la ley dice que "no haya sido posible establecer la participación de el o los responsables individuales", pero el contexto sugiere la lectura que se le da en el texto.

${ }^{74}$ Parece tratarse de una variante de lo que en la dogmática alemana se conoce como "comprobación electiva" (Wahlfeststellung), es decir, situaciones en que consta fehacientemente la concurrencia de los requisitos para una consecuencia jurídica pero existe incertidumbre respecto de detalles relevantes para la denominación del caso y a veces para los alcances de la consecuencia. Por ejemplo, cuando consta que la conducta del sujeto fue delictiva, pero no si a título de hurto o receptación, caso en el cual la incertidumbre no impide condenar, pero obliga a preferir el título de imputación más favorable. En el caso que nos ocupa la incertidumbre respecto de la identidad de quien ejecutó el delito carece de consecuencias.

${ }^{75}$ No obstante toda la discusión que provocó, especialmente en el Senado, "Historia", cit. nota n 8, pp. 257 y SS.

${ }^{76}$ Como hacía una indicación, que no prosperó, de los diputados Cardemil y Monckeberg, "Historia", cit. nota $\mathrm{n}^{\circ} 8$, p. 68.

${ }^{77}$ Así Jorge Bofill en la comisión del Senado, "Historia”, cit. nota nº 8, p. 261.
} 
HERNÁNDEZ, HÉCTOR. "La introducción de la responsabilidad penal de las personas jurídicas en Chile".

ausencia de duda razonable del art. $340 \mathrm{CPP}^{78}$ Por lo mismo, más allá del sano recordatorio, la expresión no parece prometer mayores consecuencias

Pero lo que realmente merece comentario es que en todos los demás casos de ausencia de condena al sujeto individual decae al mismo tiempo la responsabilidad penal de la persona jurídica, ${ }^{79}$ lo que no siempre resulta razonable. El caso más problemático, que al parecer tiene su origen en un lamentable error en la redacción del proyecto original, ${ }^{80}$ es el de las eximentes de responsabilidad. Por cierto nadie pondrá en duda que ése debe ser el efecto de las causas de justificación, porque sería absurdo sancionar a la persona jurídica en virtud de la comisión de hechos lícitos, pero no es en absoluto evidente que, por ejemplo, deba favorecerla a todo evento la enfermedad mental o el error de prohibición que sufre la persona natural relevante, no sólo en virtud de la adhesión general al criterio de la accesoriedad media, sino además porque se trata de hipótesis que exhiben conexiones obvias con los deberes empresariales de selección, capacitación y supervisión de personal. ${ }^{81}$

Por último, desde el punto de vista del procedimiento, la subordinación general de la responsabilidad penal de la persona jurídica a la de una persona natural perteneciente al círculo relevante de sujetos se refleja en que, salvo los casos del art. $5^{\circ}$, la formalización de la investigación contra la entidad supone la formalización al menos simultánea de la investigación o bien un requerimiento en procedimiento simplificado contra la persona natural que "pudiese comprometer la responsabilidad de la persona jurídica" de acuerdo con el art. $3^{\circ}$ (art. 22).

De lo anterior debería desprenderse con nitidez que la ley chilena no conoce nada que merezca llamarse "responsabilidad autónoma" de las personas jurídicas. Más bien al

\footnotetext{
${ }^{78}$ Lo insinuó en el Senado el abogado del Ministerio Público Antonio Segovia, "Historia", cit. nota nº 8, p. 260.

${ }^{79} \mathrm{Si}$ bien la ley no dice expresamente que la responsabilidad del ente subsiste "sólo" en los casos mencionados (como se llegó a aprobar en la Cámara de Diputados), la estructura de listado taxativo impone esa interpretación. Nótese que el proyecto original decía que la responsabilidad independiente subsistía "aun cuando" se dieran esos supuestos, lo que no excluía definitivamente otros casos.

${ }^{80} \mathrm{La}$ redacción del art. $5^{\circ} \mathrm{N}^{\circ} 3$ del proyecto del Ejecutivo era lamentable (¿una errónea adaptación de la propuesta de NIETO MARTÍN, La responsabilidad penal, cit. nota ${ }^{\circ} 26$, art. 4.2, p. 328 y s.?), pero contenía los elementos para desentrañar su probable propósito: por una parte dejaba subsistir la responsabilidad del ente en general cuando "(c)oncurrieren respecto de la persona natural alguna de las eximentes contempladas en el artículo 10 del Código Penal", para luego agregar que "(s)in perjuicio de lo anterior, si concurriere las circunstancias $\mathrm{N}^{\circ} 1$ y $\mathrm{N}^{\circ} 9$ del artículo 10 del Código Penal, se excluirá asimismo la responsabilidad legal de la persona jurídica, salvo que ésta hubiera podido y debido evitar su aparición". Combinando estas piezas se puede conjeturar que lo que se quiso decir - y por desgracia no se dijo, porque hubiera sido una solución impecable - era que las únicas eximentes que dejaban subsistente la responsabilidad penal eras las del art. 10 $\mathrm{N}^{\circ} 1$ y No $9 \mathrm{CP}$, esto es, precisamente las referidas a la culpabilidad, en tanto y en cuanto la persona jurídica "hubiera podido y debido evitar su aparición". Con todo, la crítica - totalmente justificada - fue tan fuerte ("Historia", cit. nota ${ }^{\circ} 8$, pp. 52, 69, 213) que al parecer nadie se atrevió a intentar rescatar algo del precepto, que desapareció por completo, con la consecuencia señalada en el texto.

${ }^{81}$ En lo que respecta a otras razones por las cuales podría no imponerse condena no obstante ser ésta posible, como es el caso, por ejemplo, de las salidas alternativas (suspensión condicional del procedimiento y acuerdos reparatorios), la cuestión es por cierto opinable, pero en todo caso la solución confirma el marcado carácter subordinado que la ley chilena le asigna a la responsabilidad penal de la persona jurídica.
} 
Polit. crim. Vol. 5, No 9 (Julio 2010), Art. 5, pp. 207-236.

[http://www.politicacriminal.cl/Vol_05/n_09/Vol5N9A5.pdf]

contrario, cabe preguntarse si esta subordinación tan marcada a la condena del sujeto individual, desconocida en los modelos de referencia ${ }^{82}$ e inconveniente desde el punto de vista político-criminal, ${ }^{83}$ puede considerarse satisfactoria desde la perspectiva del cumplimiento de los compromisos internacionales de Chile, más si se tiene en cuenta la preocupación especial de los órganos de la OCDE por el punto. ${ }^{84}$

\subsection{La responsabilidad por defecto de organización y sus alcances}

Éste es sin duda el elemento central del modelo: la persona jurídica no responde simplemente porque un sujeto relevante haya cometido un delito en su interés o para su beneficio, sino porque dicho delito es consecuencia del incumplimiento de sus deberes de dirección y supervisión. Con esto la ley erige formalmente a la persona jurídica en garante de vigilancia respecto de su personal y connota que los deberes de dirección y supervisión incluyen la prevención de delitos, ${ }^{85}$ al tiempo que aclara que si la entidad cumple como es debido con sus deberes no tiene responsabilidad alguna, aunque se cometa algún delito con las características previstas, simplemente porque a lo imposible - como es una garantía absoluta de ausencia de delitos - nadie está obligado.

En cuanto a los alcances de los deberes en cuestión, la ley entiende que se les ha dado debido cumplimiento cuando con anterioridad a la comisión del delito la entidad ha adoptado e implementado un "modelo de prevención" con las características que luego la propia ley detalla. ${ }^{86}$ Todo parece indicar, sin embargo, que esa forma indubitada de cumplir con los deberes en cuestión no es la única posible en el sistema de la ley, ${ }^{87}$ porque en caso

\footnotetext{
${ }^{82}$ El Decreto Legislativo italiano emplea términos mucho más amplios, y dispone que la responsabilidad del ente subsiste "aun cuando" el autor del delito no haya sido identificado o no sea imputable, así como cuando el delito se extingue por causa distinta de la amnistía (art. $8^{\circ}$ ); la propuesta de NIETO MARTíN, $L a$ responsabilidad penal, cit. nota $\mathrm{n}^{\circ} 26$, art. $4^{\circ}$, p. 328 , es coincidente, aunque más explícita en sus alcances amplios, e incluso afirma la responsabilidad - como en el Código suizo - cuando la efectiva ausencia de responsable (no sólo la imposibilidad de identificarlo) se debe al defecto de organización.

${ }^{83}$ Lo hicieron presente certeramente ante la Cámara de Diputados Miguel Soto ("Historia", cit. nota n 8, pp. 41 y ss.) y Gonzalo Medina (p. 54).

${ }^{84}$ Véase Informe Fase 1, p. 19; y, sobre todo, Informe Fase 2, p. 105, donde a propósito de un anteproyecto exhibido se expresa preocupación precisamente porque no se establece una responsabilidad realmente autónoma, en la medida en que en cada caso debía identificarse una persona natural como imputado y se requería siempre condena de la misma, entre otros aspectos relacionados. Con seguridad fue por esto que el Ejecutivo defendió tanto una fórmula como la del inciso segundo del art. $5^{\circ}$ ("Historia", cit. nota n ${ }^{\circ}$ 8, p. 257), aunque al parecer sin ver que lo más grave se filtraba por el lado de las eximentes.

${ }^{85}$ Lo que ya se viene sosteniendo sin necesidad de texto expreso respecto de los órganos directivos de las empresa y que debiera verse confirmado por esta declaración legislativa. Al respecto HERNÁNDEZ, Héctor, "Apuntes sobre la responsabilidad penal (imprudente) de los directivos de empresa", Revista de Estudios de la Justicia, $\mathrm{N}^{\mathrm{o}} 10$ (2008), pp. 175-198, pp. 186 y ss.

${ }^{86} \mathrm{El}$ inciso tercero del art. $3^{\circ}$ dispone: "Se considerará que los deberes de dirección y supervisión se han cumplido cuando, con anterioridad a la comisión del delito, la persona jurídica hubiere adoptado e implementado modelos de organización, administración y supervisión para prevenir delitos como el cometido, conforme a los dispuesto en el artículo siguiente", en tanto que el art. $4^{\circ}$ emplea la fórmula más sintética de "modelo de prevención".

${ }^{87}$ La cuestión podría haber sido meramente semántica, pues toda gestión preocupada seriamente por la prevención de delitos supone la adopción de medidas que en conjunto podría considerarse un "modelo de prevención", pero no lo es desde que luego se definen ciertas características mínimas, algunas estrictamente formales, de lo que es el modelo de prevención de la ley (art. $\left.4^{\circ}\right)$.
} 
contrario ésta hubiera previsto derechamente la inexistencia de un modelo de ese tipo como presupuesto de responsabilidad y no el incumplimiento de deberes que en principio pueden cumplirse de muy diversos modos, lo que viene confirmado por el art. $4^{\circ}$ cuando dispone que las personas jurídicas "podrán adoptar" el modelo de prevención previsto, carácter facultativo que carecería de sentido si el ejercicio de la facultad conllevara necesariamente la responsabilidad de la entidad en caso de producirse un delito relevante ${ }^{88}$. Será tarea jurisprudencial precisar cuándo las medidas de prevención delictiva adoptadas por una entidad sin modelo de prevención en los términos del art. $4^{\circ}$ pueden considerarse equivalentes a la adopción de dicho modelo $\mathrm{y}$, en consecuencia, liberan de responsabilidad. ${ }^{89}$

En todo caso, para que el modelo de prevención pueda liberar de responsabilidad no puede limitarse a un expediente meramente formal, a un simple retoque del organigrama, sino que debe constituir en los hechos una herramienta idónea de prevención, entendiendo por "idóneo", como ya se ha dicho, desde luego no una barrera infranqueable contra el delito, ${ }^{90}$ pero sí un sistema que razonablemente y conforme con lo que es exigible bajo las condiciones jurídicas y fácticas de la empresa puede obstaculizar significativamente la comisión de delitos. Es lo que se desprende de las exigencias básicas del modelo previstas en el art. $4^{\circ}$, donde nítidamente se destacan las notas de autonomía y de suficiencia de medios con que se debe dotar a la estructura de prevención, así como especialmente la necesidad de establecer métodos para la "aplicación efectiva" del modelo, considerando su supervisión, corrección y actualización ante cambios de circunstancias. ${ }^{91}$

$\mathrm{Al}$ respecto la ley prevé que las personas jurídicas puedan obtener la certificación del hecho de haber adoptado e implementado el modelo (art. $4 \mathrm{~N}^{\mathrm{o}} 4$ letra b]), ${ }^{92}$ certificación que,

\footnotetext{
${ }^{88}$ Hay razones para pensar que no era ése el propósito original. Desde luego la redacción facultativa del art. $4^{\circ}$ se introdujo recién en el Senado y hasta ese momento toda la discusión parecía discurrir sobre la base de un único mecanismo de liberación de responsabilidad (así lo entendieron, por ejemplo, los representantes del Instituto Libertad y Desarrollo, "Historia", cit. nota n ${ }^{\circ}$ 8, p. 219, y de la Confederación de la Producción y el Comercio, p. 223; véase también la discusión en la comisión del Senado sobre el art. $3^{\circ}$, pp. 239 y ss.). Incluso el senador Chadwick, quien propone el cambio de redacción que hace facultativo el modelo, parece asumir - sin ver la contradicción evidente - que esto no se opondría a que la única manera de liberarse de responsabilidad pasara por adoptarlo: "como se tratará de un sistema nuevo, desconocido en nuestro medio y que, además, estará consagrado legalmente, si no se efectúa esta precisión, podría sostenerse equivocadamente - que toda persona jurídica debería contar con este modelo, no obstante que, en realidad, el propósito es que solamente lo adopten aquellas que busquen eximirse de responsabilidad" ("Historia", cit. nota $\mathrm{n}^{\circ} 8$, p. 265, énfasis agregado), como si pudiera haber otra razón para hacerlo.

${ }^{89}$ Para que el diseño legal no sea letra muerta, el modelo de prevención previsto por el art. $4^{\circ}$ debe operar necesariamente como parámetro - material, ya que no formal - de cumplimiento de los deberes de prevención delictiva: se aceptan otras estrategias, pero sólo en la medida en que sean tan idóneas como el modelo legal.

${ }^{90}$ Como indican las Guidelines estadounidenses, “(e)1 fracaso en prevenir o detectar el actual delito no significa necesariamente que el programa [de cumplimiento] no sea en general efectivo para prevenir y detectar la conducta criminal" (§8B2.1 [a] [2]).

${ }^{91}$ Con total independencia de que, a instancia del senador Gómez, se haya suprimido la referencia a que el modelo se hubieran adoptado e implementado "eficientemente", "porque la definición de lo que es eficiente corresponde a un juicio de exculpación subjetivo, lo que resulta improcedente en la consagración de una eximente", "Historia", cit. nota n ${ }^{\circ}$ 8, p. 241.

92 "Las personas jurídicas podrán obtener la certificación de la adopción e implementación de su modelo de prevención de delitos. En el certificado constará que dicho modelo contempla todos los requisitos establecidos
} 
Polit. crim. Vol. 5, № 9 (Julio 2010), Art. 5, pp. 207-236.

[http://www.politicacriminal.cl/Vol_05/n_09/Vol5N9A5.pdf]

conforme a los antecedentes legislativos, debería fundar una presunción de cumplimiento de los deberes de dirección y supervisión en favor de la entidad. ${ }^{93}$ De los mismos antecedentes $-\mathrm{y}$, sobre todo, de la letra de la ley, que en rigor no menciona presunción de ningún tipo - se desprende que se trata de una presunción simplemente legal que puede ser desvirtuada por el Ministerio Público. ${ }^{94}$

Como es obvio, la existencia de este mecanismo probatorio implica que, en caso de no contar con certificado, es la empresa la que debe demostrar que ha cumplido con sus deberes de dirección y supervisión. Si bien en principio puede verse en esto una inversión de la carga de la prueba, no puede desconocerse que cuando un sujeto especialmente relacionado con una persona jurídica comete un delito directa e inmediatamente en interés de ella o para su provecho es muy probablemente porque algo no está funcionando bien en la entidad, de modo que el delito es un indicio fuerte de incumplimiento de deberes que pesan sobre la misma. Si esto es así, no parece objetable que el Ministerio Público pueda descansar al menos en principio en ese indicio, limitándose a acreditar los dos primeros requisitos de la responsabilidad en tanto la entidad no aporte antecedentes plausibles del debido cumplimiento de sus deberes. ${ }^{95}$

No es posible abordar con un mínimo detalle las implicancias del modelo de prevención previsto por la ley chilena, las que en el futuro deberían ser objeto privilegiado de análisis y

en los numerales 1), 2) y 3) anteriores, en relación a la situación, tamaño, giro, nivel de ingresos y complejidad de la persona jurídica".

${ }^{93}$ La posibilidad de certificación tiene su origen en una propuesta del Ejecutivo en el Senado ("Historia", cit. nota $\mathrm{n}^{\circ}$ 8, p. 247 y ss.), donde expresamente se le daba al certificado el carácter de "presunción legal" de la existencia y pertinencia del modelo adoptado. Si bien luego se suprimió esa explicitación, esto fue por meros avatares técnicos, sin que nadie pusiera en duda la función del certificado. Por lo demás, es de la esencia de cualquier certificación que dé fe de ciertos hechos o circunstancias fácticas, lo que en este caso se ve fortalecido por el hecho de que los certificados sólo puedan ser expedidos por "empresas de auditoría externa, sociedades clasificadoras de riesgo u otras entidades registradas ante la Superintendencia de Valores y Seguros que puedan cumplir esta labor, de conformidad a la normativa que, para estos efectos, establezca el mencionado organismo fiscalizador", entidades que por expreso mandato legal cumplen una "función pública" en los términos del art. $260 \mathrm{CP}$, con lo cual sus empleados quedan equiparados para todos los efectos legales a los empleados públicos (art. $4^{\circ} \mathrm{N}^{\circ} 4$, letra c]).

${ }^{94}$ Como se dijo, ése era el carácter que expresamente le atribuía el Ejecutivo, y fue el sentido que en todo momento se le dio en el debate ("Historia", cit. nota $\mathrm{n}^{\circ} 8$, pp. 250 y ss.). Esto se vio significativamente reforzado, además, por la supresión de buena parte de la reglamentación originalmente propuesta (doble control: certificación inicial del modelo y posterior auditoría periódica de su funcionamiento; plazos de vigencia de los certificados), que si bien no obstaba a la prueba en contrario, contribuía a que los certificados parecieran cuanto menos que incontrovertible en la práctica. Al relajarse las exigencias en aras de evitar costos excesivos a las empresas (véase el debate en "Historia", cit. nota $n^{\circ} 8$, pp. 253 y ss.), se rebajó en igual medida el valor de la presunción, aunque sin duda sigue siendo un resguardo importante.

${ }^{95}$ El aspecto probatorio ha sido especialmente discutido en Italia, donde la inversión de la carga de la prueba, al menos respecto de los delitos cometidos por órganos directivos, es manifiesta y muy exigente, pues se dispone que la entidad no responde "si prueba que" se ha adoptado e implementado eficientemente modelos de prevención idóneos, que la competencia de vigilar el funcionamiento y cumplimiento de los modelos y de velar por su actualización ha estado a cargo de un órgano con poderes autónomos, que el sujeto ha cometido el delito eludiendo fraudulentamente los modelos, y que no ha habido omisión o insuficiencia de vigilancia (art. 6.1). Al respecto, críticamente, CERQUA, Luigi Domenico, La responsabilità da reato degli enti, Matelica: Halley, 2006, p. 65 y ss. Respecto de delitos de subordinados, en cambio, el texto legal es mucho más tenue (art. 7), muy similar al texto chileno. 
HERNÁNDEZ, HÉCTOR. "La introducción de la responsabilidad penal de las personas jurídicas en Chile".

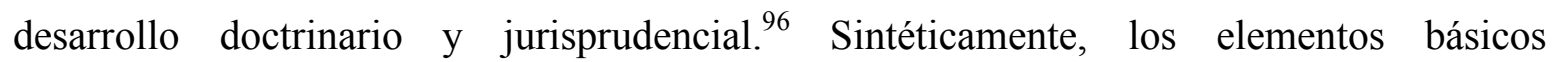
considerados en el art. $4^{\circ}$ son los siguientes:

a) La designación de un encargado de prevención dotado de autonomía. ${ }^{97}$

b) La provisión de los medios y facultades suficientes para el desempeño de sus funciones, entre los que deben considerarse a lo menos:

a. Los recursos y medios materiales necesarios, en consideración al tamaño y capacidad económica de la persona jurídica.

b. Acceso directo a la administración para informar oportunamente por un medio idóneo, de las medidas y planes implementados en el cumplimiento de su cometido y para rendir cuenta de su gestión y reportar a lo menos semestralmente.

c) El establecimiento de un sistema de prevención de delitos, que debe ponerse en conocimiento de todos los trabajadores y colaboradores ${ }^{98}$ y contemplar a lo menos lo siguiente:

a. La identificación de las actividades o procesos de la entidad en cuyo contexto se genere o incremente el riesgo de comisión de delitos. ${ }^{99}$

b. El establecimiento de protocolos, reglas y procedimientos específicos que permitan a quienes intervengan en tales actividades o procesos programar $\mathrm{y}$ ejecutar sus tareas o labores de una manera que prevenga la comisión de delitos.

c. La identificación de los procedimientos de administración y auditoría de los recursos financieros que permitan a la entidad prevenir su utilización en delitos.

d. La existencia de sanciones internas, así como de procedimientos de denuncia o persecución de responsabilidades pecuniarias en contra de las personas que incumplan el sistema de prevención de delitos.

\footnotetext{
${ }^{96}$ Para lo cual con seguridad será de mucha utilidad el capítulo octavo de las mencionadas Sentencing Guidelines estadounidenses y la experiencia acumulada a su respecto.

${ }^{97}$ Esta última exigencia de autonomía no rige respecto de empresas pequeñas: "En el caso de las personas jurídicas cuyos ingresos anuales no excedan de cien mil unidades de fomento, el dueño, el socio o el accionista controlador podrán asumir personalmente las tareas del encargado de prevención".

98 Los elementos del sistema (obligaciones, prohibiciones, sanciones, etc.) deben incorporarse en los reglamentos que la persona jurídica dicte al efecto y comunicarse a todos los trabajadores, además de ser incorporada expresamente en los respectivos contratos de trabajo y de prestación de servicios de todos los trabajadores, empleados y prestadores de servicios de la persona jurídica, incluidos los máximos ejecutivos de la misma.

${ }^{99}$ Se entiende, aquí y en lo sucesivo, que se está haciendo referencia a los delitos previstos en el art. $1^{\circ}$.
} 
Polit. crim. Vol. 5, № 9 (Julio 2010), Art. 5, pp. 207-236.

[http://www.politicacriminal.cl/Vol_05/n_09/Vol5N9A5.pdf]

d) El establecimiento de métodos para la aplicación efectiva del modelo de prevención de los delitos y su supervisión a fin de detectar y corregir sus fallas, así como actualizarlo de acuerdo al cambio de circunstancias de la respectiva entidad.

\section{Penas y procedimiento (síntesis)}

En materia de penas, la ley no se aparta mayormente de lo que es habitual en el derecho comparado. Las penas principales previstas en el art. $8^{\circ}$ son las siguientes:

a) Disolución de la persona jurídica o cancelación de la personalidad jurídica. ${ }^{100}$

b) Prohibición temporal o perpetua de celebrar actos y contratos con los organismos del Estado.

c) Pérdida parcial o total de beneficios fiscales o prohibición absoluta de recepción de los mismos por un período determinado.

d) Multa a beneficio fiscal.

Por su parte, el art. 13 prevé como penas accesorias la publicación de un extracto de la sentencia a costa de la persona jurídica condenada, el comiso del producto "y demás bienes, efectos, objetos, documentos e instrumentos" del delito y, cuando el delito suponga la inversión de recursos de la persona jurídica superiores a los que ella genera, el entero en arcas fiscales de una cantidad equivalente a la inversión realizada.

Salvo la disolución y la prohibición perpetua de celebrar actos o contratos con el Estado, así como las penas accesorias, todas las penas conocen distintos grados (arts. 10 a 12). Para los efectos de la determinación de las penas la ley distingue entre penas de crímenes ${ }^{101}$ y de simples delitos (arts. 14 y 15), a partir de lo cual la libertad del juez para aplicar todas o alguna de las penas previstas y la extensión en que puede hacerlo está supeditada a la concurrencia de las circunstancias atenuantes ${ }^{102}$ o agravantes ${ }^{103}$ específicamente previstas para las personas jurídicas (art. 16) y, dentro de ese marco, a unos criterios específicos de individualización judicial de la pena, orientados principalmente a la gravedad del delito y a

\footnotetext{
${ }^{100}$ Esta pena no se aplica a las empresas del Estado ni a las personas jurídicas de derecho privado que presten un servicio de utilidad pública cuya interrupción pudiere causar graves consecuencias sociales y económicas o daños serios a la comunidad, como resultado de la aplicación de dicha pena ( $\operatorname{art} .8^{\circ} \mathrm{N}^{\mathrm{o}} 1$ ). Asimismo, sólo se puede aplicar tratándose de crímenes (en la actualidad, sólo lavado de dinero) y siempre que medie la circunstancia agravante del art. $7^{\circ}$, de haber sido condenada por el mismo delito en los últimos cinco años (art. 16 inciso segundo). Su ejecución se regula en el art. $9^{\circ}$.

${ }^{101}$ En la actualidad el único crimen previsto es el lavado de dinero.

102 Son circunstancias atenuantes las del $\mathrm{N}^{\mathrm{o}} 7$ (procurar con celo reparar el mal causado o impedir sus ulteriores perniciosas consecuencias) y $\mathrm{N}^{\circ} 9$ (colaborar sustancialmente al esclarecimiento de los hechos, lo que en este caso se entiende especialmente cumplido cuando, antes de conocer que el procedimiento se dirige contra ella, los representantes de la persona jurídica ponen el hecho punible en conocimiento de las autoridades o aportan antecedentes para establecerlo) del art. $11 \mathrm{CP}$ y la de adoptar, antes del comienzo del juicio, medidas eficaces para prevenir la reiteración de la misma clase de delitos objeto de la investigación $\left(\operatorname{art} 6^{\circ}\right)$.

${ }^{103}$ La única circunstancia agravante consiste en que la persona jurídica haya sido condenada por el mismo delito durante los últimos cinco años $\left(\right.$ art. $\left.7^{\circ}\right)$.
} 
HERNÁNDEZ, HÉCTOR. "La introducción de la responsabilidad penal de las personas jurídicas en Chile".

las circunstancias de la entidad, pero también al posible impacto negativo de la pena en terceros del entorno de la misma (art. 17). ${ }^{104}$

Por último, la responsabilidad penal de la persona jurídica se extingue por las mismas causas que rigen para las personas naturales conforme al art. $93 \mathrm{CP}$, salvo la muerte del sujeto (art. 19), en vez de lo cual se regulan, bajo el término ciertamente poco feliz de "transmisión de la responsabilidad penal de la persona jurídica", los casos de transformación, fusión, absorción, división o disolución voluntaria de la entidad (art. 18). ${ }^{105}$ Esta última regulación, muy similar a la del derecho italiano, ${ }^{106}$ está llamada a evitar la elusión de la responsabilidad penal de las entidades por medio de meras operaciones jurídicas formales.

En cuanto al procedimiento, se aplican en lo fundamental las reglas del Código Procesal Penal para las personas naturales, con algunas adaptaciones puntuales, como la ya mencionada subordinación general de la formalización de la investigación contra la persona jurídica al mismo trámite o al requerimiento contra la persona natural relacionada (art. 22), la exclusión del principio de oportunidad (art. 24) y una regulación especial de la procedencia y alcances de la suspensión condicional del procedimiento (art. 25), del procedimiento simplificado (art. 26), del procedimiento abreviado (art. 27) y de la suspensión de la condena (art. 29). Con todo, no parece residir en esas adaptaciones el núcleo verdaderamente problemático desde un punto de vista procesal, sino en los alcances de los derechos y garantías de la persona jurídica, así como en la regulación de su representación.

\footnotetext{
${ }^{104}$ Que son los siguientes: "1) Los montos de dinero involucrados en la comisión del delito. 2) El tamaño y la naturaleza de la persona jurídica. 3) La capacidad económica de la persona jurídica. 4) El grado de sujeción y cumplimiento de la normativa legal y reglamentaria y de las reglas técnicas de obligatoria observancia en el ejercicio de su giro o actividad habitual. 5) La extensión del mal causado por el delito. 6) La gravedad de las consecuencias sociales y económicas o, en su caso, los daños serios que pudiere causar a la comunidad la imposición de la pena, cuando se trate de empresas del Estado o de empresas que presten un servicio de utilidad pública".

105 "En el caso de transformación, fusión, absorción, división o disolución de común acuerdo o voluntaria de la persona jurídica responsable de uno o más de los delitos a que se refiere el art. $1^{\circ}$, su responsabilidad derivada de los delitos cometidos con anterioridad a la ocurrencia de alguno de dichos actos se transmitirá a la o las personas jurídicas resultantes de los mismos, si las hubiere, de acuerdo a las reglas siguientes, todo ello sin perjuicio de los derechos de terceros de buena fe. 1) Si se impone la pena de multa, en los casos de transformación, fusión o absorción de una persona jurídica, la persona jurídica resultante responderá por el total de la cuantía. En el caso de división, las personas jurídicas resultantes serán solidariamente responsables del pago de la misma. 2) En los casos de disolución de común acuerdo de una persona jurídica con fines de lucro, la multa se transmitirá a los socios y partícipes en el capital, quienes responderán hasta el límite del valor de la cuota de liquidación que se les hubiere asignado. 3) Si se trata de cualquiera otra pena, el juez valorará, atendiendo a las finalidades que en cada caso se persiguen, su conveniencia. Para adoptar esta decisión deberá atender sobre todo a la continuidad sustancial de los medios materiales y humanos y a la actividad desarrollada. 4) Desde que se hubiere solicitado la audiencia de formalización de la investigación en contra de una persona jurídica sin fines de lucro y hasta la sentencia absolutoria o condenatoria y en tanto ésta no esté cumplida, no podrá concederse la autorización del inciso primero del artículo 559 del Código Civil".

${ }^{106}$ A partir del art. 28 del Decreto Legislativo No 231/2001.
} 
Polit. crim. Vol. 5, № 9 (Julio 2010), Art. 5, pp. 207-236. [http://www.politicacriminal.cl/Vol_05/n_09/Vol5N9A5.pdf]

Porque si bien la ley hace aplicables a la persona jurídica las disposiciones que establecen derechos y garantías del imputado, acusado y condenado (art. 21), ${ }^{107}$ ella misma matiza luego precisando que esto rige "siempre que aquéllas resulten compatibles con la naturaleza específica de las personas jurídicas”. ${ }^{108}$ En este contexto probablemente la cuestión más relevante sea la de si a la entidad le asiste el derecho a guardar silencio (art. 93 letra g] $\mathrm{CPP}$ ), con la consecuencia de que el representante pudiera alegar por y para ella ${ }^{109}$ dicho derecho y negarse a declarar o a entregar material incriminatorio contra la entidad (fundamentalmente documentación de todo tipo), sin que le fueran aplicables los apremios o penalidades previstas para los terceros renuentes. La cuestión se ha discutido en el derecho comparado, donde - con razón, a nuestro juicio - parece predominar la tesis negativa. ${ }^{110}$ En todo caso, se encuentra completamente abierta en el derecho chileno. ${ }^{111}$

En materia de representación de la persona jurídica, llama la atención que la ley no haya regulado los evidentes conflictos de interés que pueden surgir en un sistema diseñado para reprimir tanto a la entidad como a la persona natural que haya cometido el delito y que

${ }^{107}$ El derecho a contar con un defensor penal público, previsto por el art. 102 CPP y al cual el art. 21 se remite expresamente, se encuentra en todo caso reiterado en el art. 28.

${ }^{108}$ El matiz rige también para aquéllas disposiciones individualmente mencionadas en el inciso segundo del art. 21, como lo confirma la situación del art. 93 letra h) CPP, que consagra el derecho a "(n)o ser sometido a tortura ni a otros tratos crueles, inhumanos o degradantes".

${ }^{109}$ Desde luego la situación es clara si el representante es al mismo tiempo imputado o, sin serlo, se encuentra en la situación del art. $305 \mathrm{CPP}$, sin perjuicio de que, como en seguida se explica, debiera revisarse en ese caso la continuidad de su personería.

${ }^{110}$ Especialmente en los Estados Unidos se mantiene de un modo tajante que las entidades no pueden invocar la garantía. Esto es así desde Wilson v. U.S., 221 U.S. 361 (1911), donde, de la mano precursora de Hale v. Henkel, 201 U.S. 43 (1906), se argumentó que las personas jurídicas, en cuanto creación del Estado, gozaban sólo de los derechos que éste consentía en concederles, cual precisamente no era el caso del privilegio contra la autoincriminación, contexto en el cual se le asignó especial importancia a la larga tradición de poderes de fiscalización del Estado sobre las personas jurídicas, a lo que U.S. v. White, 322 U.S. 694 (1944) agregó consideraciones históricas sobre el significado radicalmente personal (equivalente a la prohibición de tortura) del privilegio (al respecto, ANÓNIMO, "Corporate Crime: Regulating Corporate Behavior through Criminal Sanctions", Harvard L. Rev., 92 [1979], pp. 1227-1325, pp. 1277 y ss.; también GOBERT / PUNCH, Rethinking, cit. $\mathrm{n}^{\mathrm{o}}$ 42, p. 196 y ss.). Para el derecho contravencional alemán lo ha negado también el Tribunal Constitucional Federal de ese país, en su fallo BVerfGE 95, 220 de 1997, con base en que los derechos fundamentales basados en cualidades, formas de expresión o relaciones privativas de las personas naturales no son traspasables a las personas jurídicas en cuanto construcciones del ordenamiento jurídico, lo que concreta luego explicando cómo el nemo tenetur se funda en la dignidad humana, si bien siembra dudas cuando termina enfatizando las particularidades del derecho contravencional, que precisamente lo diferencian del derecho penal (BVerfGE 220, 242). Sobre la situación en otros ordenamientos, DROPE, Katharina, Strafprozessuale Probleme bei der Einführung einer Verbandsstrafe, Berlin: Duncker \& Humblot, 2002, p. 158 y ss.

${ }^{111}$ Durante la tramitación en el Senado y sobre la base de un texto idéntico (pues, como se ha dicho, la mayor explicitación a través del inciso segundo agregado después no resuelve el asunto), Jorge Bofill planteó su preocupación por el punto ("Historia", cit. nota n ${ }^{\circ}$ 8, pp. 214 y s.). En la misma sede, a favor de una respuesta afirmativa se mostró el abogado del Ministerio de Justicia Ignacio Castillo: "Lo novedoso de este precepto [el inciso segundo del art. 21]... es que podría entenderse que también está referido al representante legal de la empresa, lo que es muy importante, por ejemplo, para los efectos del derecho de auto incriminarse. Explicó que si el representante legal es citado en calidad de testigo, habría que indicarle que tiene derecho a guardar silencio para no imputar a la empresa" ("Historia", cit. nota $n^{\circ}$ 8, p. 296, énfasis agregado). Un completo panorama del tipo de consecuencias que podría tener el reconocimiento del principio nemo tenetur para las personas jurídicas en DROPE, Strafprozessuale Probleme, cit. nota n ${ }^{\circ}$ 110, pp. 202 y ss. 
HERNÁNDEZ, HÉCTOR. "La introducción de la responsabilidad penal de las personas jurídicas en Chile".

incluso prevé que bajo ciertas condiciones sólo responda la persona jurídica. Se comprenderá que en ese escenario la tentación de obtener una atenuación más o menos significativa de la pena e incluso, eventualmente, la impunidad a costa de la persona jurídica puede ser enorme. Es por eso que se echa de menos la regulación prevista tanto en el proyecto como en el texto aprobado inicialmente por la Cámara de Diputados (art. 25), ${ }^{112}$ que preveía, tal como ocurre en el derecho italiano o francés, ${ }^{113}$ el reemplazo del representante cuando el procedimiento se dirigiera también contra él. La razón extraoficial para haber prescindido de la misma, consistente en que en ese caso la permanencia del representante dependería de un acto discrecional del Ministerio Público (la formalización de la investigación), puede ser atendible en principio, pero razonablemente sólo podía justificar una formulación más cautelosa, abierta a la ponderación judicial, pero en caso alguno la total prescindencia de regulación. ${ }^{114}$ El punto no sólo es relevante desde la perspectiva del status de la entidad, sino también y en primera línea para evitar que la responsabilidad penal de las personas jurídicas se convierta en fuente de impunidad para los directivos o empleados involucrados.

\section{Balance provisional y desafíos}

De lo precedentemente expuesto fluye una valoración que en términos generales es positiva. De entre los múltiples modelos disponibles se ha adoptado uno que responde a las conclusiones del debate comparado más actual y que se muestra razonable y equilibrado. Ciertamente hay cuestiones de detalle que deberían mejorarse, pero que, en la mayor parte de los casos, admiten interpretaciones funcionales a las líneas generales del modelo.

Para el futuro, el primer gran desafío del nuevo régimen legal consiste, obviamente, en que el modelo de responsabilidad previsto reciba efectiva aplicación. Si bien la parquedad del catálogo inicial de delitos relevantes no favorece las cosas, es perfectamente imaginable que en el mediano plazo casos de soborno o aun de lavado de dinero den lugar a las primeras experiencias con la ley. En ese contexto se podrá apreciar si la práctica es capaz de darle una interpretación razonable a las piezas potencialmente disfuncionales del sistema o si, por el contrario, se requiere intervención legislativa, no en último término para honrar las obligaciones internaciones de Chile. Sobre esa base debería ampliarse el campo de aplicación de la ley a los delitos más relevantes relacionados con la actividad empresarial.

En particular, se presenta el desafío más estructural y de largo plazo de desarrollar efectivamente una cultura empresarial de autorregulación en materia de prevención delictiva. Al efecto será indispensable una práctica punitiva efectiva y con preferencia por criterios materiales por sobre los meramente formales, que demuestre que la ley no es una

\footnotetext{
${ }^{112}$ El inciso segundo del art. 25 era del siguiente tenor: "Si se formalizare una investigación con respecto a dicho representante por el mismo hecho punible por el cual se investiga la responsabilidad penal de la persona jurídica, cesará su representación, y el tribunal solicitará al órgano competente de aquélla la designación de un nuevo representante, dentro del plazo que le señale. Si transcurrido el tiempo fijado por el tribunal, no se notifica de la designación ordenada, el tribunal designará al efecto un curador ad litem".

${ }^{113}$ En Italia en el art. 39.1 del Decreto Legislativo No 231/2001; en Francia en el art. 760-43 CPP

${ }^{114}$ Está por verse si la norma general de garantía del art. 10 CPP puede ser una vía para que jueces atentos a esta situación puedan reaccionar en casos que sugieren la realidad del peligro esbozado.
} 
Polit. crim. Vol. 5, № 9 (Julio 2010), Art. 5, pp. 207-236.

[http://www.politicacriminal.cl/Vol_05/n_09/Vol5N9A5.pdf]

mera fachada cosmética, y que al mismo tiempo cumpla con la promesa de que las empresas que cumplen seriamente con sus deberes no tienen nada que temer.

Por último, si bien no es propio de la responsabilidad penal de las personas jurídicas, un desafío de la mayor importancia es que ésta no se convierta en los hechos en una puerta ilegítima e indeseada de escape para los sujetos individuales que han intervenido en la actividad criminal. ${ }^{115}$ Sobre todo en el contexto actual en Chile, en que lentamente parece ir avanzándose hacia una práctica de imputación que apunta más a hacer efectiva la responsabilidad de los órganos por el incumplimiento - precisamente - de sus deberes de supervisión, ${ }^{116}$ representaría un retroceso lamentable que en el nuevo régimen legal se viera una razón para restringir esos criterios de imputación.

\section{BIBLIOGRAFÍA}

ALCALDE, Enrique, "Relaciones entre la pena administrativa y la sanción penal", Revista de Derecho Administrativo Económico, № 14 (2005), pp. 29-34

ANÓNIMO, "Corporate Crime: Regulating Corporate Behavior through Criminal Sanctions”, Harvard L. Rev., 92 (1979), pp. 1227-1325

BACIGALUPO, Silvina, La responsabilidad penal de las personas jurídicas, Barcelona: Bosch, 1998

BACIGALUPO, Silvina, "Las consecuencias accesorias aplicables a las personas jurídicas en el Código penal de 1995", en: BACIGALUPO, Enrique (Director), Curso de derecho penal económico, Madrid - Barcelona: Marcial Pons, 1998, pp. 65-86

BAIGÚN, David, La responsabilidad penal de las personas jurídicas, Buenos Aires: Depalma, 2000

BRAITHWAITE, John, "Enforced Self-Regulation: a new strategy for corporate crime control", Mich. L. Rev., 80 (1981-1982), pp. 1466-1507

BUSTOS, Juan, "Perspectivas actuales del derecho penal económico", Gaceta Jurídica, № 132 (1991), pp. 7-15

BUSTOS, Juan, "La responsabilidad penal de las personas jurídicas", en: MAIER, Julio; BINDER, Alberto (Compiladores), El derecho penal hoy. Homenaje al Prof. David Baigún, Buenos Aires: Editores del Puerto, 1995, pp. 15-26\}

CERQUA, Luigi Domenico, La responsabilità da reato degli enti, Matelica: Halley, 2006

COUSIÑO, Luis, Derecho penal chileno, T. I, Santiago: Editorial Jurídica de Chile, 1975

CURY, Enrique, "Algunas reflexiones sobre la relación entre penas penales y administrativas", Boletín de Investigaciones de la Facultad de Derecho de la Pontificia Universidad Católica de Chile, No 44/45 (1979/1980), pp. 86-94

\footnotetext{
${ }^{115}$ Advierten sobre esto FEIJÓO SÁNCHEZ, "Sobre el fundamento", cit. nota no 25, pp. 242 y ss.; y MIR PUIG, Santiago, "Una tercera vía en materia de responsabilidad penal de las personas jurídicas", Revista Electrónica de Ciencia Penal y Criminología, 06-01 (2004), pp. 1-17, p. 16 y s., en: http://criminet.ugr.es/recpc/06/recpc06-01.pdf [visitado el 30.03.2010].

${ }^{116}$ En la literatura chilena HERNÁNDEZ, "Apuntes", cit. nota no 85, pp. 175 y ss.; VAN WEEZEL, Alex, "Intervención delictiva y garantismo penal", ZIS, 8-9/2009, pp. 432-445, passim, en: http://www.zisonline.com/dat/artikel/2009 8-9 350.pdf [visitado el 30.03.2010]; si bien algo más restrictivo, también NOVOA, Juan Pablo, "Responsabilidad penal de los órganos directivos de la empresa", Actualidad Jurídica, $\mathrm{N}^{\mathrm{o}} 18$ (julio 2008), pp. 431-472, passim.
} 
HERNÁNDEZ, HÉCTOR. "La introducción de la responsabilidad penal de las personas jurídicas en Chile".

CURY, Enrique, Derecho penal. Parte general, $7^{\circ}$ edición, Santiago: Ediciones Universidad Católica de Chile, 2005

DEL RÍO, J. Raimundo, Derecho penal, T. II, Santiago: Nascimento, 1935

DEL VILLAR, Waldo, Manual de derecho penal. Parte general, Valparaíso: Edeval, 1985

DROPE, Katharina, Strafprozessuale Probleme bei der Einführung einer Verbandsstrafe, Berlin: Duncker \& Humblot, 2002

EIDAM, Gerd, Unternehmen und Strafe, 3. Aufl., Köln: Luchterhand, 2008

ETCHEBERRY, Alfredo, Derecho penal, $3^{\circ}$ edición, T. I y T. II, Santiago: Editorial Jurídica de Chile, 1998

FEIJÓO SÁNCHEZ, Bernardo, "Sobre el fundamento de las sanciones penales para personas jurídicas y empresas en el derecho penal español y el derecho penal peruano", en: GARCÍA CAVERO, Percy (Coordinador), La responsabilidad penal de las personas jurídicas, órganos y representantes, Lima: ARA, 2002, pp. 215-275

FRISCH, Wolfgang, "Problemas fundamentales de la responsabilidad penal de los órganos de dirección de la empresa". Trad. PAREDES CASTAÑÓN, José Manuel, en: MIR PUIG, Santiago; LUZÓN PEÑA, Diego Manuel (Coordinadores), Responsabilidad penal de las empresas y sus órganos y responsabilidad por el producto, Barcelona: J.M. Bosch, 1996, pp. 99-127

GARCÍA CAVERO, Percy, La persona jurídica en el derecho penal, Lima: Grijley, 2008

GARRIDO, Mario, Derecho penal, T. II, Santiago: Editorial Jurídica de Chile, 1992

GOBERT, James; PUNCH, Maurice, Rethinking corporate crime, London: Butterworths, 2003

GÓMEZ-JARA DÍEZ, Carlos, "Corporate Criminal Liability”, en: GARCÍA CAVERO, Percy (Coordinador), La responsabilidad penal de las personas jurídicas, órganos y representantes, Lima: ARA, 2002, pp. 277-327

GÓMEZ-JARA DÍEZ, Carlos, La culpabilidad penal de la empresa, Madrid - Barcelona: Marcial Pons, 2005

GÓMEZ-JARA DÍEZ, Carlos, “Autoorganización empresarial y autorresponsabilidad empresarial”, Revista Electrónica de Ciencia Penal y Criminología, 08 - 05 (2006), pp. 1-27, en: http://criminet.ugr.es/recpc/08/recpc08-05.pdf

GÓMEZ-JARA DIEZ, Carlos, "El nuevo artículo 31.2 del Código penal”, en: GÓMEZJARA DÍEZ, Carlos (Editor), Modelos de autorresponsabilidad empresarial, Cizur Menor: Thomson-Aranzadi, 2006, pp. 239-309

GÓMEZ-JARA DÍEZ, Carlos, La responsabilidad penal de las empresas en los EE. UU., Madrid: Editorial Universitaria Ramón Areces, 2006

HEFENDEHL, Roland, "Corporate Governance und Business Ethics: Scheinberuhigung oder Alternativen bei der Bekämpfung der Wirtschaftskriminalität? ”, JZ, 2006, pp. 119-125

HEINE, Günter, Die strafrechtliche Verantwortlichkeit von Unternehmen, Baden-Baden: Nomos, 1995

HERNÁNDEZ, Héctor, "Perspectivas del derecho penal económico en Chile", Persona y Sociedad, Vol. XIX No 1 (2005), pp. 101-134

HERNÁNDEZ, Héctor, "El delito de lavado de dinero", en: AA. VV., Informes en derecho, Santiago: Ministerio Público, 2005, pp. 321-354 
Polit. crim. Vol. 5, № 9 (Julio 2010), Art. 5, pp. 207-236.

[http://www.politicacriminal.cl/Vol_05/n_09/Vol5N9A5.pdf]

HERNÁNDEZ, Héctor, "El régimen de la autointoxicación plena en el derecho penal chileno: deuda pendiente con el principio de culpabilidad", Revista de Estudios de la Justicia, No 9 (2007), pp. 11-45

HERNÁNDEZ, Héctor, "Apuntes sobre la responsabilidad penal (imprudente) de los directivos de empresa", Revista de Estudios de la Justicia, No 10 (2008), pp. 175-198

JAKOBS, Günther, Strafrecht AT, 2. Aufl., Berlin - New York: De Gruyter, 1991

LARGUIER, Jean; CONTE, Philippe, Droit pénal des affaires, $11^{e}$ édition, Paris: Armand Colin, 2004

LATORRE, Patricio, "Las sociedades estatales en el ordenamiento jurídico chileno", Revista de Derecho (PUCV), T. XXX (2008 - I), pp. 223-240

MACKINNON, John, Autoría y participación y el delito de receptación, Santiago: LexisNexis, 2004

MATUS, Jean Pierre, "Informe sobre algunos aspectos sustantivos y procesales del delito de lavado de dinero del art. 12 de la Ley 19.366", en: AA. VV., Informes en derecho, Santiago: Ministerio Público, 2005, pp. 305-319

MATUS, Jean Pierre, "Informe sobre el proyecto de ley que establece la responsabilidad legal de las personas jurídicas en los delitos de lavado de activos, financiamiento del terrorismo y delitos de cohecho que indica, Mensaje 018-357', Ius et Praxis, año 15, No 2 (2009), pp. 285-306

MIR PUIG, Santiago, "Una tercera vía en materia de responsabilidad penal de las personas jurídicas", Revista Electrónica de Ciencia Penal y Criminología, 06-01 (2004), pp. 117, en: http://criminet.ugr.es/recpc/06/recpc06-01.pdf

MODOLELL, Juan Luis, Persona jurídica y responsabilidad penal, Caracas: Universidad Central de Venezuela, 2002

MORENO, Carlos, "Responsabilidad penal de las personas jurídicas, sus órganos y directivos en derecho penal económico", Revista Entheos, Año 2, No 1 (2004), pp. 43-69

NÁQUIRA, Jaime, Derecho penal. Teoría del delito, Santiago: McGraw-Hill, 1998

NIETO MARTÍN, Adán, La responsabilidad penal de las personas jurídicas, Madrid: Iustel, 2008

NIETO MARTÍN, Adán, "Responsabilidad social, gobierno corporativo y autorregulación: sus influencias en el derecho penal de la empresa", Polit. Crim., No 5 (2008), A3-5, pp. 1-18, en: http://www.politicacriminal.cl/n_05/A_3_5.pdf

NOVOA, Eduardo, Curso de derecho penal chileno, T. I, Santiago: Editorial Jurídica de Chile, 1960

NOVOA, Eduardo, Curso de derecho penal chileno, T. II, Santiago: Editorial Jurídica de Chile, 1966

NOVOA, Juan Pablo, "Responsabilidad penal de los órganos directivos de la empresa", Actualidad Jurídica, No 18 (julio 2008), pp. 431-472

ONFRAY, Arturo, "Reflexiones en torno a la responsabilidad penal de las personas jurídicas", Revista de Derecho (CDE), № 4 [No 1 del año 2] (2001), pp. 153-167

ORTIZ, Luis, "Delincuencia económica", en: AA. VV., Problemas actuales de derecho penal, Temuco: Universidad Católica de Temuco, 2003, pp. 191-226

POLITOFF, Sergio, "El lavado de dinero", en: POLITOFF, Sergio; MATUS, Jean Pierre (Coordinadores), Lavado de dinero y tráfico ilícito de estupefacientes, Santiago: ConoSur, 1999, pp. 3-86 
HERNÁNDEZ, HÉCTOR. "La introducción de la responsabilidad penal de las personas jurídicas en Chile".

POLITOFF, Sergio, "El 'autor detrás del autor'. De la autoría funcional a la responsabilidad penal de las personas jurídicas", en: POLITOFF, Sergio; MATUS, Jean Pierre (Coordinadores), Gran criminalidad organizada y tráfico ilícito de estupefacientes, Santiago: ConoSur, 2000, pp. 333-414

POLITOFF, Sergio; MATUS, Jean Pierre; RAMÍREZ, María Cecilia, Lecciones de derecho penal chileno. Parte general, $2^{\circ}$ edición, Santiago: Editorial Jurídica de Chile, 2004

PRAMBS, Claudio, El delito de blanqueo de capitales, Santiago: LexisNexis, 2005

RIED, José Miguel, "El caso Consorcio 2 - Banco de Chile: información privilegiada y potestad sancionatoria de la administración”, Sentencias Destacadas, 2005, pp. 31-44

RODRÍGUEZ SOL, Luis, Registro domiciliario y prueba ilícita, Granada: Comares, 1998

SAMSON, Erich, "Absicht und direkter Vorsatz im Strafrecht", JA, 1989, pp. 449-454

SCHÜNEMANN, Bernd, "La punibilidad de las personas jurídicas desde la perspectiva europea”, Trad. PEÑARANDA RAMOS, Enrique; PÉREZ MANZANO, Mercedes, en: AA. VV., Hacia un derecho penal económico europeo. Jornadas en honor del Prof. Klaus Tiedemann, Madrid: BOE, 1995, pp. 565-600

SILVA, Pedro, "La responsabilidad penal de las personas jurídicas", Revista de Ciencias Penales, T. IV (1938), pp. 317-329

SILVA SÁNCHEZ, Jesús María, "La responsabilidad penal de las personas jurídicas y las consecuencias accesorias del art. 129 del Código penal", Manuales de Formación Continuada, $\mathrm{N}^{\mathrm{o}} 14$ (2001), pp. 307-364

SILVA SÁNCHEZ, Jesús María, "La aplicación judicial de las consecuencias accesorias para las empresas", InDret, 2/2006, pp. 1-15, en: http://www.indret.com/pdf/342_es2.pdf

STRADER, J. Kelly, Understanding white collar crime, Newark etc.: LexisNexis, 2002

THEILE, Hans, "Unternehmensrichtlinien: Ein Beitrag zur Prävention von Wirtschaftskriminalität?", ZIS, 9/2008, pp. 406-418, en: http://www.zisonline.com/dat/artikel/2008 9261.pdf

TIEDEMANN, Klaus, Wirtschaftsstrafrecht und Wirtschaftskriminalität AT, Reinbek bei Hamburg: Rowohlt, 1976

TIEDEMANN, Klaus, 'Die 'Bebußung' von Unternehmen nach dem 2. Gesetz zur Bekämpfung der Wirtschaftskriminalität”, NJW, 1988, pp. 1169-1174

VAN WEEZEL, Alex, "Intervención delictiva y garantismo penal”, ZIS, 8-9/2009, pp. 432445, en: http://www.zis-online.com/dat/artikel/2009_8-9 350.pdf

VERGARA, Alejandro, "Esquema de los principios del derecho administrativo sancionador", Revista de Derecho (UCN-Coquimbo), año 11 No 2 (2004), pp. 137147

WARDA, Heinz-Günter, “Grundzüge der strafrechtlichen Irrtumslehre”, Jura, 1979, pp. 14, 71-82, 113-118, 286-297

WERNER, Gerhard, Bekämpfung der Geldwäsche in der Kreditwirtschaft, Freiburg: Iuscrim Edition (MPI), 1996

ZUGALDÍA ESPINAR, José Miguel, Responsabilidad penal de empresas, fundaciones y asociaciones, Valencia: Tirant lo Blanch, 2008

ZÚÑIGA RODRÍGUEZ, Laura, Bases para un modelo de imputación de responsabilidad penal a las personas jurídicas, $2^{\circ}$ edición, Cizur Menor: Thomson-Aranzadi, 2003 